\title{
Intelligence-Based Design Illustrated with Examples of ACROS Fukuoka, KKL Luzern and MICA Changsha Buildings-A Multicriterial Case Study
}

\author{
Beata Majerska-Pałubicka (D) and Elżbieta Latusek * \\ Faculty of Architecture, Silesian University of Technology, Akademicka 7, 44-100 Gliwice, Poland; \\ beata.majerska-palubicka@polsl.pl \\ * Correspondence: latusek.elzbieta@tlen.pl; Tel.: +48-608-035-396
}

check for updates

Citation: Majerska-Pałubicka, B.; Latusek, E. Intelligence-Based Design Illustrated with Examples of ACROS Fukuoka, KKL Luzern and MICA Changsha Buildings-A Multicriterial Case Study. Buildings 2021, 11, 135. https://doi.org/ 10.3390/buildings11040135

Academic Editors: Miimu Airaksinen and Isabel Pinto Seppä

Received: 2 February 2021

Accepted: 22 March 2021

Published: 25 March 2021

Publisher's Note: MDPI stays neutra with regard to jurisdictional claims in published maps and institutional affiliations.

Copyright: (c) 2021 by the authors. Licensee MDPI, Basel, Switzerland. This article is an open access article distributed under the terms and conditions of the Creative Commons Attribution (CC BY) license (https:// creativecommons.org/licenses/by/ $4.0 /)$.

\begin{abstract}
The article concerns the issue of intelligence-based design, which, during the design process undertaken by architects, signifies (according to the authors of the article) thinking about perceptual involvement in the built environment, designing together with people and for people and not forgetting about conveniences brought by technological progress. The way to smart cities, in respect of architectural solutions, leads (to a significant extent) through the smart design of multifunctional buildings based on the idea of sustainable development. The article-related research involved multiple case studies including three buildings, i.e., Asian Cross Road Over the Sea (ACROS) in Fukuoka, Kultur- und Kongresszentrum Luzern (KKL) in Luzern and Changsha Meixihu International Contemporary Art Museum (MICA) in Changsha. The above-named buildings, located in different countries, i.e., Japan, Switzerland and China, respectively, and erected within various time spans, i.e., the 1990s-2020, are characterized by primary common features-multifunctionality, large cubature and comparable program elements. The research presented in this article aimed to find and present the elements of intelligence-based design in the buildings and perform their comparative analysis taking into consideration the fact that the buildings were erected within the span of 30 years. The article presents a graphic comparative analysis of the intelligence-based design, a multicriterial case study (encompassing the concept, functional and spatial solutions and structure) of selected architectural objects. The article includes also a graphic comparative analysis of the very objects and concert halls: Fukuoka Symphony Hall (ACROS), Salle Blanche (KKL) and Hunan Grand Theatre (MICA).
\end{abstract}

Keywords: intelligence-based design; smart architecture; smart buildings; smart cities; smart design; sustainable development; ACROS Fukuoka; KKL Luzern; MICA Changsha

\section{Introduction}

Historical architectural structures frequently show that architecture is capable of conveying a lot of important contents even after thousands of years following their creation. This fact reveals how important it is to properly transfer content using the language of architecture. The built environment is determined by landscape filled with architectural structures. Therefore, civilizations are remembered, among other things, due to buildings, which, similar to paintings or sculptures, are a universal medium enabling the transfer of information. By applying appropriate technologies or the system of functions, the architect can affect addressees' impressions and behavior.

Research on architecture provides information about possibilities of improving the environment, among other things, by human intelligence. "Collective research into the dimensions of human perception and neuro-connectivity has recently related the most immediate measures of architecture and design to human experience" [1]. Neurophysiological, i.e., perceptual, involvement in the built environment determines what it is about being a human and helps people function in the surrounding physical world. Adaptive design consisting of the adjustment of space to users' needs is human in its own nature and 
in every dimension. Therefore, it is, to some extent, antithetic in relation to modern design, seen as the use of innovative technologies and recent IT development (e.g., parametric design) enabling the creation of increasingly complex forms and shapes [2]. It should be noted that architecture, in all of its forms-from simple to complex ones, must be based on structural principles present in the physical world. At the same time, it is essential to profoundly understand human needs, actions and neurophysiological (perceptual) mechanisms. The theory based on intelligence-based design stresses the existence of a close relationship between the mind and the manner, i.e., the direct neurological evaluation of an existing surface, structure, pattern, texture and form, which can be related to the code of architecture. By specifying the aforesaid code, the architect defines the frames of a given design (adopted architectural style, characteristic shapes, materials, etc.). The best way to the creation of advanced smart cities leads through intelligence-based design. Smart cities are elements that are connected by means of technical, electronic, traffic, circulation and urban development (including green areas) systems forming spatial and functional structures. Buildings-the multifunctional complexes being components of the abovementioned structures often create local municipal centers. These centers are currently often based on the idea of sustainable development. In order to play their role in smart cities, such centers cannot be just equipped with technological novelties and electronic design.

Jan Bagiński states that "As we look back, it appears that, when it comes to architecture, the copying of patterns was always a common practice-not only justified, but even wanted. However, a presently noticeable change is the enormous number of patterns and their dynamic interweaving" [3]. The ability to read the physical environment constitutes an evolving set of abilities to process information, which the human mind, owing to direct experience, has developed over thousands of years. Presently, not only the domain of architecture must face globalization and tackle the increasing number of issues in the process of work. Recent decades have seen the worldwide development of increasingly complex building permit designs and the distinction between theory based on intelligence-based design and that based on smart architecture. According to some researchers, currently smart architecture goes beyond a good design as it "combines client's needs, smart technology and an effective design. There can also exist a smart building or space interacting with the surroundings and adapting to user's needs" [4].

On the other hand, there is an increasing number of architects, for whom the ideas of smart architecture, smart buildings and smart cities constitute a paradigm for undertaking activities consisting in the "adaptation to the surrounding environment", defining the notion of a smart buildings as "sustainable in terms of energy and water consumption (... ) healthy as regards the wellbeing of persons living and working in it and functional in accordance with users' needs" [5]. Smart architecture constitutes an integral solution to various design challenges including the environmental issues, the optimum use of space, natural resources, materials and technology and aesthetics [6].

A smart building can be complex both structurally and technologically, but not more complicated than necessary. In this case, technology is an important tool, not a goal in itself. Sometimes, apparently a dumb building (being in opposition to a smart building), directly and simply connected with intelligence-based design can be smarter than a technologydominated building machine over which the user may lose control. The use of advanced engineering and materials and "decorating" a building solely with ecological attributes being, in fact, just gadgets, is not necessarily smart. On the other hand, mistrust of technological solutions is not always justified. However, owing to intelligence-based design, buildings exemplifying smart architecture may be a model design approach. Such an approach surprisingly easily implements assumptions of inscribing the building into an existing context and the need for adjusting to user's needs, as is the case with the buildings under consideration.

Widely defined intelligence-based design signifies thinking of perceptual involvement in the built environment, designed together with and for people and not forgetting about conveniences brought by technological development. The architect should not at any cost 
seek to distinguish individual design-related trends but is rather obliged to combine their various aspects for the common good of the building users. The same applies to smart buildings designed in and for smart cities, which should harmonize not only systemically but also in relation to sustainable development and design for people. Three architectural objects were selected for investigations: Prefectural International Hall Asian Cross Road Over the Sea (ACROS), Kultur- und Kongresszentrum Luzern (KKL) and Changsha Meixihu International Contemporary Art Museum (MICA). The criteria taken into consideration at the selection stage were as follows: location; different cultures (Europe, Asia); various time spans of implementation (late 20th century-early 21st century); functional and spatial solutions (multifunctionality, large cubatures and comparable program elements) and application of elements intelligence-based design.

\section{Materials and Methods}

\subsection{Research Questions}

In architecture, there is no casus of one proper solution. Design is always a process, the results of which may always surprise in different ways and on various planes.

The subject literature studies were carried out with a view to the application of intelligence-based design in the investigated buildings and the continuation of the design concept concerning smart buildings in the context of smart urban development and intelligence-based design over the span of 30 years. Prefectural International Hall Asian Cross Road Over the Sea was built in 1995, Kultur und Kongresszentrum Luzern was finally opened in 2000, whereas Changsha Meixihu International Contemporary Art Museum opened its gates to visitors in 2019 (Grand Theatre earlier in 2017). Taking the above into consideration, as there is no ideal single solution to the designing issues, in the same way there is no end to the questions related to the architecture and general process of designing. The article poses three research questions, which aim to extend and deepen the comparative studies mainly based on graphic and table comparisons:

Taking into account the above, the following questions were posed to define the direction of the research:

- Is it possible to find the continuation of the design concept in the context of smart design in the buildings subjected to research?

- Why is it so important to expertly use intelligence-based design at the design stage?

- To what extent should the architect respond to stakeholders' (developers, city dwellers, etc.) wishes and how does it relate to the rational transformation of matter, taking into account functionality and adjustment to social and ecological aspects?

Searching for the answers to the posed questions, the researchers investigated, among other things, the impact of functional and spatial solutions applied in the studied buildings on rational transformation of matter and the influence of the adjustment to social aspects (such as addressing city inhabitants' needs) on the designing process. One of the inspirations to take up the research in this scope was Emilio Ambasz's statement: "It is a moral duty to show that a different future is possible. We have to demonstrate another model of life to alter the course of the here and now" [7].

\subsection{Multiple Case Study}

While describing the relationship between intelligence-based design and smart cities, it should be emphasized that smart cities as such do not constitute a research criterion in this article. The criterion of the comparative assessment is the buildings created on the grounds of intelligence-based design, which can serve smart cities. It is not only the number of electronic gadgets that makes buildings intelligent. It is also the designing based on various solutions used, among others, by the authors of the above-mentioned concepts: Emilio Ambasz, Jean Nouvel and the design studio Zaha Hadid Architects.

Intelligence-based design deliberately "manipulates" the built environment in order to effectively engage people into complex and well-organized development of the information system. A theory based on intelligence speaks about a close relationship between mind 
and matter. This refers to a neurological assessment of forms and structures, the ways of "reading out" the physical environment and the ability to process information, which the human brain has been developing for millennia due to human experience [8]. Human beings forming a community may positively influence the development of cities by their organized and collective ("mass") activities. Such social-design activities should be the first done in buildings and then move onto the urban-planning scale [8]. The design thinking based on intelligence was initially described by Christopher Alexander in his book for architects and urban planners "A Pattern Language" [9]. His way of thinking, particularly in the scope of application of design patterns, was adopted by the circles of IT specialists.

Smart cities take advantage of the methods connected with the introduction of electronics into urban areas. They collect data that serve the purpose of effective management and improvement of activities taking place in urbanized areas [10,11]. Technologies connected with smart cities enable the municipal authorities to directly interact with the community infrastructure and to monitor what goes on in the city and how the city is developing. The collected information, in the form of databases, should be used in the intelligence-based design with the purpose of improvement of such aspects as: quality of city services, reduction of both costs and the use of resources and increase in contacts between authorities and inhabitants of "smart cities" [12].

The research discussed in the article involved the use of a multiple case study, aimed to compare three multifunctional buildings, i.e., ACROS in the city of Fukuoka (Hakata), KKL in Luzern and MICA in Changsha. The application of case study was treated as a method of presentation based on the description of a single event. Such a method made it possible to draw conclusions concerning the causes of a given phenomenon and the results. The above-named study belongs to a group of comparative (qualitative) methods and is defined as an "empirical test investigating a current phenomenon profoundly and in the actual context, particularly where borders between the phenomenon and the context are blurred" [13]. In the multicriterial case study, which, by assumption, takes into consideration at least several criteria.

It should be emphasized that the goal-being an objective presentation of vast multilayered relationships between investigated levels (the product in the form of a building, the context in the form of a city with all its problems, the process in the form of activities using intelligence-based design, the context of achievement of the sustainable built environment harmonizing with the natural environment) - is attained only when the investigations are conducted in a simultaneous way because then they give a full, holistic picture of the underlying relationships $[14,15]$. The analysis of the design process and that of the object construction must be performed parallel to the analysis of the product and context. Such an analysis encompasses the decision-making level, the level of the connections network between the design process participants and design process elements and the level of continuation of the process including the participation of users and taking into account their comments and opinions. What is essential is the figure of the designer themselves with their personal views, commitment and decision-making process. According to R. Fogué, the most demanding aspect is the analysis of the process itself due to the transitory nature of situations and studied elements, which must be spotted and interpreted [13]. What is also difficult in the interpretation of contextual facts is the transition from a subjective approach to an objective one. Therefore all investigated elements were treated as equally important.

In the case of the above-mentioned buildings, the investigations were conducted taking into consideration the analyses of the following:

- City and the problem-ways and methods of solving social and spatial problems by using architectural solutions correlated with the intelligence-based design;

- Architect and the concept-outlining the figure of the creator of a given architectural concept, the context of the site where the building was constructed, introduction to historical context in order to investigate what aspects of the intelligence-based design were applied by the architects;

- Building and functional-spatial solutions-in what way the formation of the building's body influenced the solutions to the above-described issue; description of functional 
and spatial solutions of a given architectural object taking into account building development formation, ecological aspects or solutions used in the interior;

- Concert hall—each of the above-listed objects features concert halls of comparable sizes; they constitute an inherent part of these objects and hold together various functions of the objects, which is the reason why they were also subjected to analysis.

In addition, some selected aspects were discussed using graphic visuals in order to explain, in a better way, the existing differences or similarities in the comparative analysis.

\subsection{Graphic Comparative Analyses}

Architectural design is the process of creating a new reality. The sketchy image of the design usually aims to briefly convey the design idea. The article contains tabulated images constituting the graphic comparative analyses of the multifunctional buildings under consideration, where designs are presented as the process of creative thinking. The performance of research based on visual aspects helps understand the development of the design idea and better specify components of the buildings subjected to research-related multicriterial analysis.

\subsection{Prefectural International Hall "Asian Cross Road Over the Sea" (ACROS), Fukuoka, Japan}

\subsubsection{City and the Problem}

Fukuoka is the largest city on the Japanese island of Kyusyu. It is an important regional centre of commerce, transport (seaport of Hakata) and business and a well-known centre of science, culture and international congresses. The name of the Prefectural International Hall ACROS located in Fukuoka (Figure 1) derives from the Asian Cross Road Over the Sea, signifying seaside crossroads. At a certain point, the city of Fukuoka urgently needed to erect a new government office building. The only site available in the city centre was the public Tenjin Central Park having an area of two hectares [16]. The city authorities decided to develop the land within the framework of a joint venture with a private company [16]. It was assumed that, within the project, the commercial developer would lease the land for sixty years and declare the erection of the building. A part of the building was to be dedicated to public and communal activities, whereas the remaining space was supposed to generate income [17]. Once it had become commonly known that the building was to be located in the city's last green area, the residents of Fukuoka started to intensely oppose the investment [18].

\subsubsection{Architect and the Concept}

The ACROS building (Figure 2) was designed by Emilio Ambasz, a lecturer at Princeton, Carnegie Institute of Technology in Pittsburgh and Hochschule für Gestaltung in Ulm, Germany, and the Curator of Design in New York's MOMA. Since the early years of his career, long before environment-related discussions became popular worldwide, Ambasz's works, characterized by the reinterpretation of the relationship between architecture and landscape, contained designs embedded in nature [18]. It can undoubtedly be asserted that Ambasz is one of the founding fathers of the pioneer trend of green architecture (Ambasz's statement from his official website www.ambasz.com (accessed on 15 November 2020): "seeing others using vegetation in their projects makes me realise that my mission is starting to show signs of development. Hearing some of them affirming the paternity of such ideas makes me feel like a mythological character, even though I know that this is only a foreseen Freudian destiny"). Ambasz believed that the architecture must be pragmatic, yet its main reason for existence is emotional commotion [19]. It can be assumed that the method of design used by the architect does not belong to any specific period of time but is nearly timeless. As a result, Ambasz's "design behaviour" can still inspire subsequent generations of architects. The design concept by Emilio Ambasz influenced many well-known creators of modern architecture including Renzo Piano, Jean Nouvel and Tadao Ando (Tadao Ando's comment on the ACROS: "I believe there is no other work where nature dominates in architecture with such 
force and grace [... ] Emilio Ambasz has taught us to imagine a dimension where nature and architect are inseparable, in a realm containing both God's and human creation" [9]).

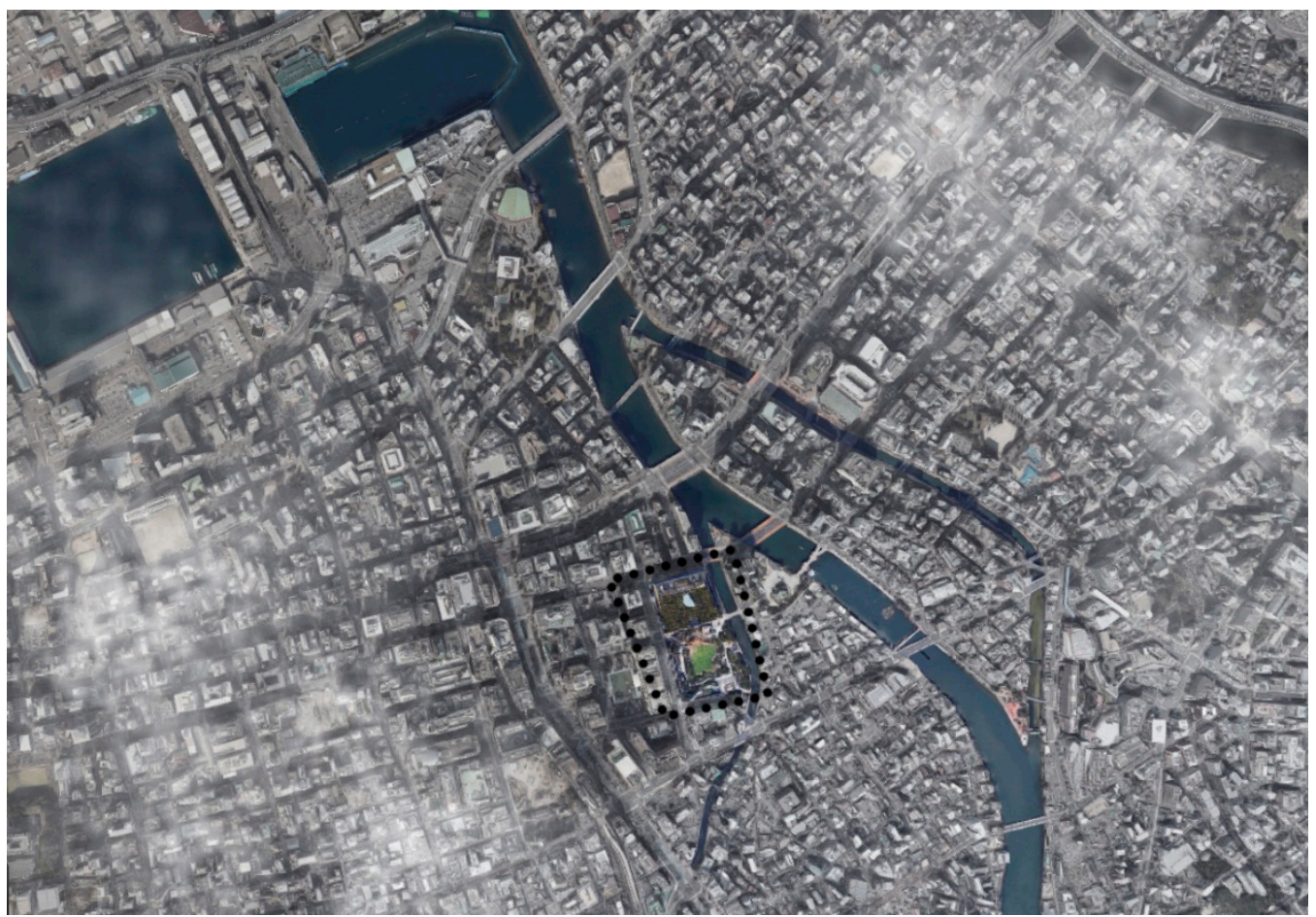

Figure 1. Location of the Prefectural International Hall "Asian Cross Road Over the Sea" in the city of Fukuoka, Japan; graphic processing, based on Google Maps, by E. Latusek.

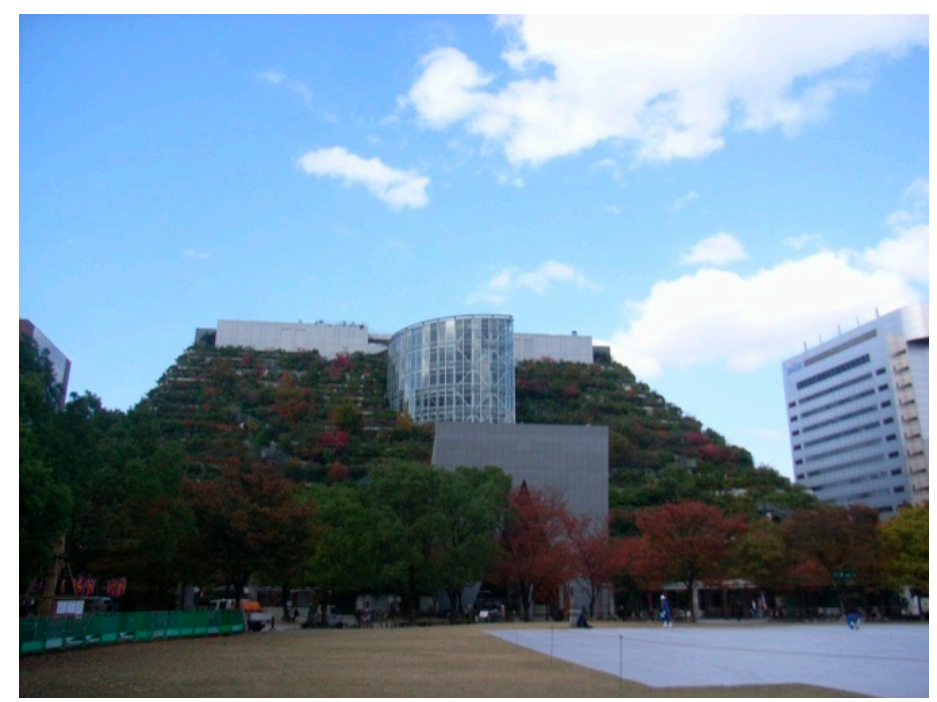

Figure 2. Green façade of the Prefectural International Hall "Asian Cross Road Over the Sea" from the side of the Tenjin Central Park; photograph by B. Majerska-Pałubicka.

Emilio Ambasz's vision of the ACROS fully addressed the need for green areas in the city centre and, at the same time, provided economic effectiveness without escalating the conflict with the city residents [18]. The architect reconciled opposite needs, i.e., the maintaining of the original size of the Tenjin Central Park and providing the city with an extensive multifunctional structure in its centre. The design involves the use of a number of garden terraces (Figure 3), which by rising, return to the citizens of Fukuoka nearly the 
entire park greenery taken by the building [16]. The architect designed the building so that the park space would continue on terrace roofs, thus integrating the building with public space [18]. Ambasz's use of intelligence-based design completely eliminated delays in the construction, which might have happened due to social challenges [16]. In the creator's opinion, the ACROS, constituting a breakthrough design vision in the 1990s, proved irrefutably that the dominant concept, according to which "cities are for buildings and suburbs are for park spaces", was wrong. The architect claimed then that it was far too easy to degrade nature in suburbs and leave greyness in the city [7]. The ACROS design received many awards due to the assumption that greenery should cover the greyness of buildings and that architect's goal was to return the area where the building was erected to the local community. The concept also proves that in densely populated cities it is possible to interweave developers' interests, the need for new buildings and open public space.

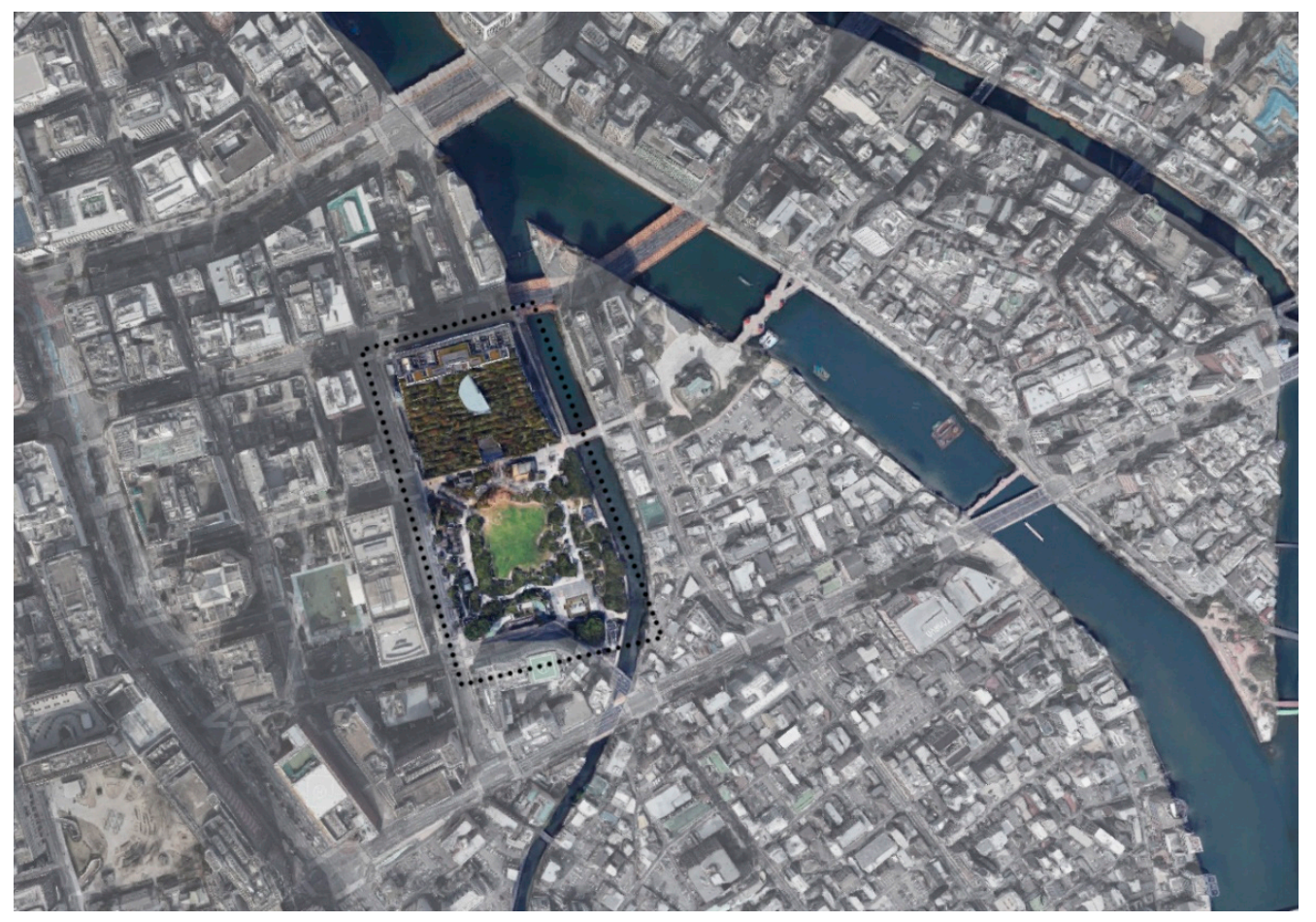

Figure 3. Context of the Prefectural International Hall "Asian Cross Road Over the Sea"; graphic processing, based on Google Maps and [19], by E. Latusek.

\subsubsection{Building and Functional-Spatial Solutions}

Emilio Ambasz, designing in accordance with the idea of sustainable development, successfully retained the green area of the Tenjin Central Park by creating 15 low stepped terraces, thus making up for the human intervention in nature (environmental aspect). The building seems to smoothly "transform" into the park with the entire south façade through a number of terrace gardens. The last area of greenery in the city centre of Fukuoka was "saved", additionally providing space ideal for exercising, meditation and relaxation far from the bustling city (social aspect). Standing in the park and looking at the building arouses the impression of a "green hill" or a "green pyramid". When climbing up the zigzag stairs to enter the garden on the roof, visitors can hear the sound of cascade waterfalls. While on the roof, visitors can view the harbor and nearby mountains. The ground floor of the building provides a free passage between the city park and the busy main street (Figure 4). 


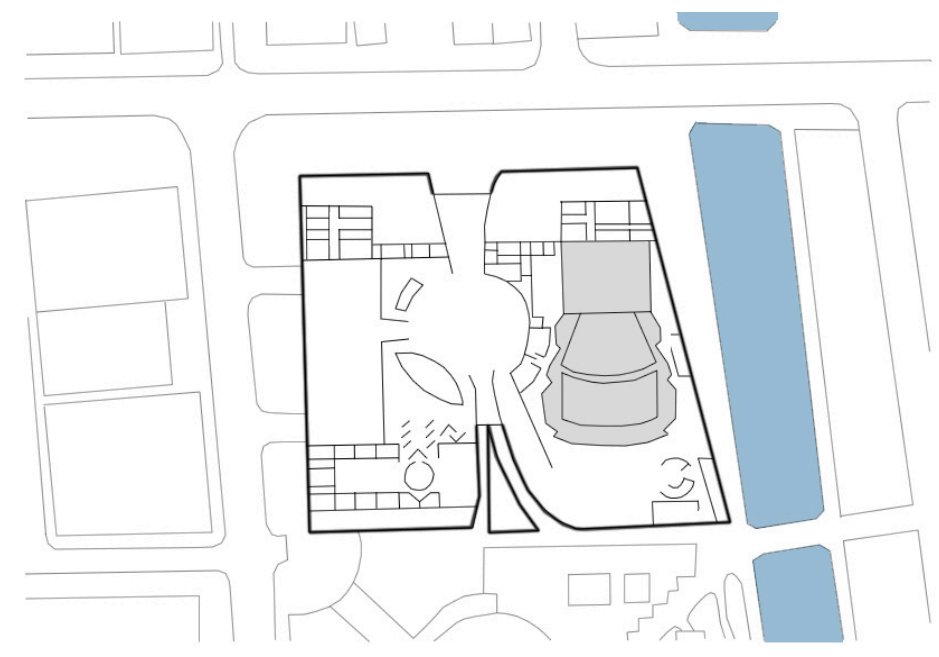

Figure 4. Projection of the Prefectural International Hall "Asian Cross Road Over the Sea"; graphic processing, based on Google Maps and [20], by E. Latusek.

The main, i.e., northern, façade of the building facing the city's most important financial street, is a traditional, glazed, municipal façade clearly divided into horizontal strips designated by individual stories (Figure 5). The building houses galleries, music rehearsal rooms, seminar and conference rooms (e.g., International Conference Hall for 100 participants fitted with facilities for international conferences, e.g., booths for simultaneous interpreters, a VIP lounge, a study and a waiting room) enabling the organization of international meetings, scientific conferences, information sessions and seminars [21]. The building also houses 16 smaller conference rooms for subsessions of international conferences, study meetings and lectures, the event hall holding 900 spectators with a 12-element stage adjustable to various types of events such as theatrical performances, exhibitions, concerts, fashion shows and lectures and the Fukuoka Symphony Hall for 1867 spectators [21].

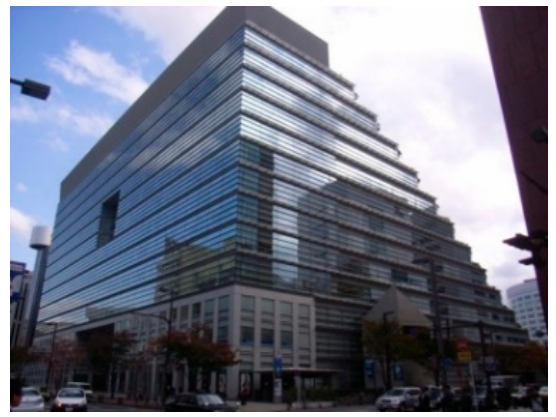

(a)

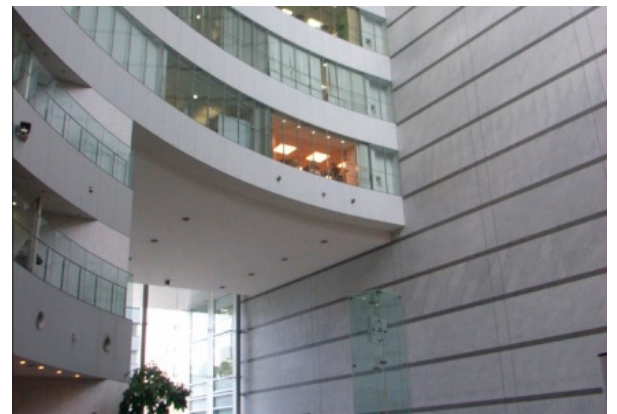

(b)

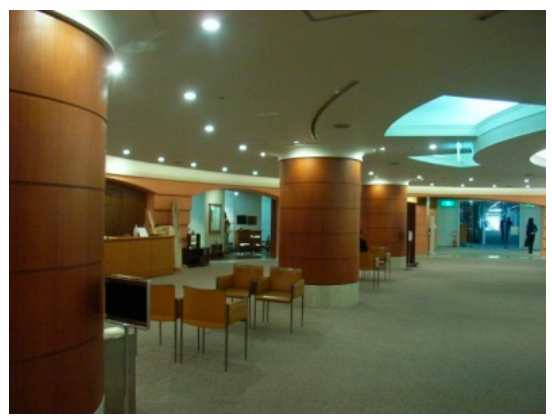

(c)

Figure 5. Prefekturalna Hala Międzynarodowa "Asian CrossRoad Over the Sea": (a) Elewacja północna; (b) Wewnętrzne foyer and (c) Wnętrze w części administracyjnej, photograph by B. Majerska-Pałubicka.

The ACROS interior has an area of $97,000 \mathrm{~m}^{2}$ and includes, among other things, an exhibition function, a museum, a theatre for 2000 spectators, a congress hall, government office rooms and private rooms, a tourist information centre, shops and four underground stories. The venue is a meeting place both for Fukuoka residents and tourists travelling throughout Japan [7]. A cultural information centre provides visitors with information about cultural events taking place in the prefecture of Fukuoka and other prefectures of Kyusyu. The Takumi Gallery houses a permanent exhibition of traditional crafts and organizes temporary exhibitions every week. The building is an example of a successful investment as commercial facilities generate income (economic aspect of sustainable devel- 
opment), whereas its external green façade is used by many city residents, constituting a green sanctuary in the concrete jungle of the Fukuoka city centre.

\subsubsection{Fukuoka Symphony Hall}

The ACROS is a venue of various international events. The Fukuoka Symphony Hall (Figure 6) can seat 1867 spectators at three levels [22]. Owing to specific acoustic panels, the fully equipped shoe-box-type concert hall enables the obtainment of variable reverberation and, as a result, rich and beautiful sounds. The hall is adapted for symphonic, chamber and opera orchestras. For years, the hall has hosted world-famous concerts of chamber music, amateur recitals and performances and extra-music events including scientific conferences and lectures. Events are accompanied by exhibitions presenting Fukuoka's traditional art and crafts. Various aspects of local culture are presented through dedicated festivals such as the ACROS Classic Fiesta, the Fukuoka Early Music Festival or the Karuta Festival [21]. The Fukuoka Symphony Hall also houses the Arena Hall, i.e., a small multifunctional hall for chamber events, performances and exhibitions and the Cultural Gallery, i.e., an exhibition hall containing space for free and creative cultural activity available to exhibitors of artistic works and creators of cultural events. The hall also has seminar rooms and five rooms for music rehearsals, supporting cultural activities [21].

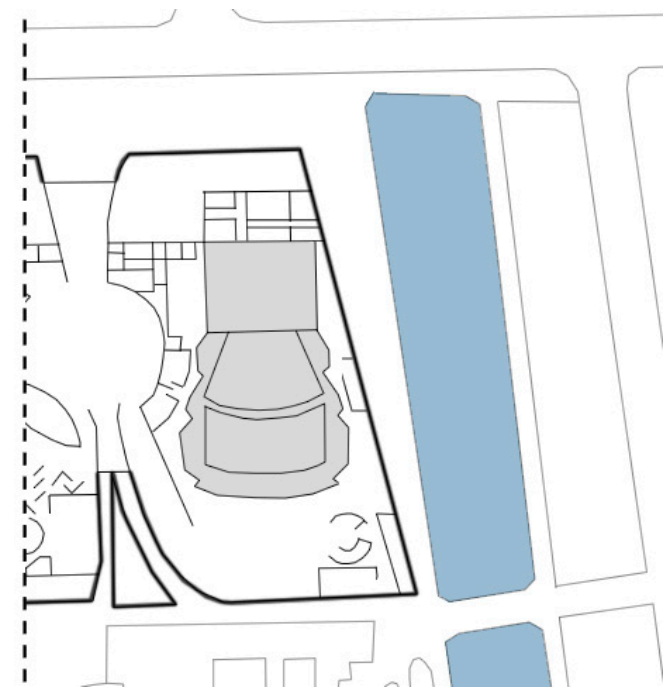

Figure 6. Fukuoka Symphony Hall in the Prefectural International Hall "Asian Cross Road Over the Sea", graphic processing, based on [23] by E. Latusek.

\subsection{Kultur- und Kongresszentrum Luzern, Lucerne, Switzerland}

\subsubsection{City and the Problem}

Lucerne (Luzern) is a historic city located on the west shore of Lake Lucerne, also known as Lake of the Four Forested Settlements, at the foot of the Pilatus mountain in Switzerland (Figure 7). The city has a very long history and landscape-based tourist tradition. Every year, the city hosts a medieval Christmas fair next to a preserved fragment of defensive walls on the northern hill [24]. The city is also known for such events as the Blue Balls Festival, i.e., an annual festival of contemporary music [25] and the Lucerne Festival, i.e., a cyclic festival of classical music held since 1938 [26]. Initially, the venue of the Lucerne Festival was the old Art and Congress Centre designed by Armin Meili. After years of good service, in 1980, the condition of the building was recognized as bad and the need for renewing the image of the place was given some thought [27]. 


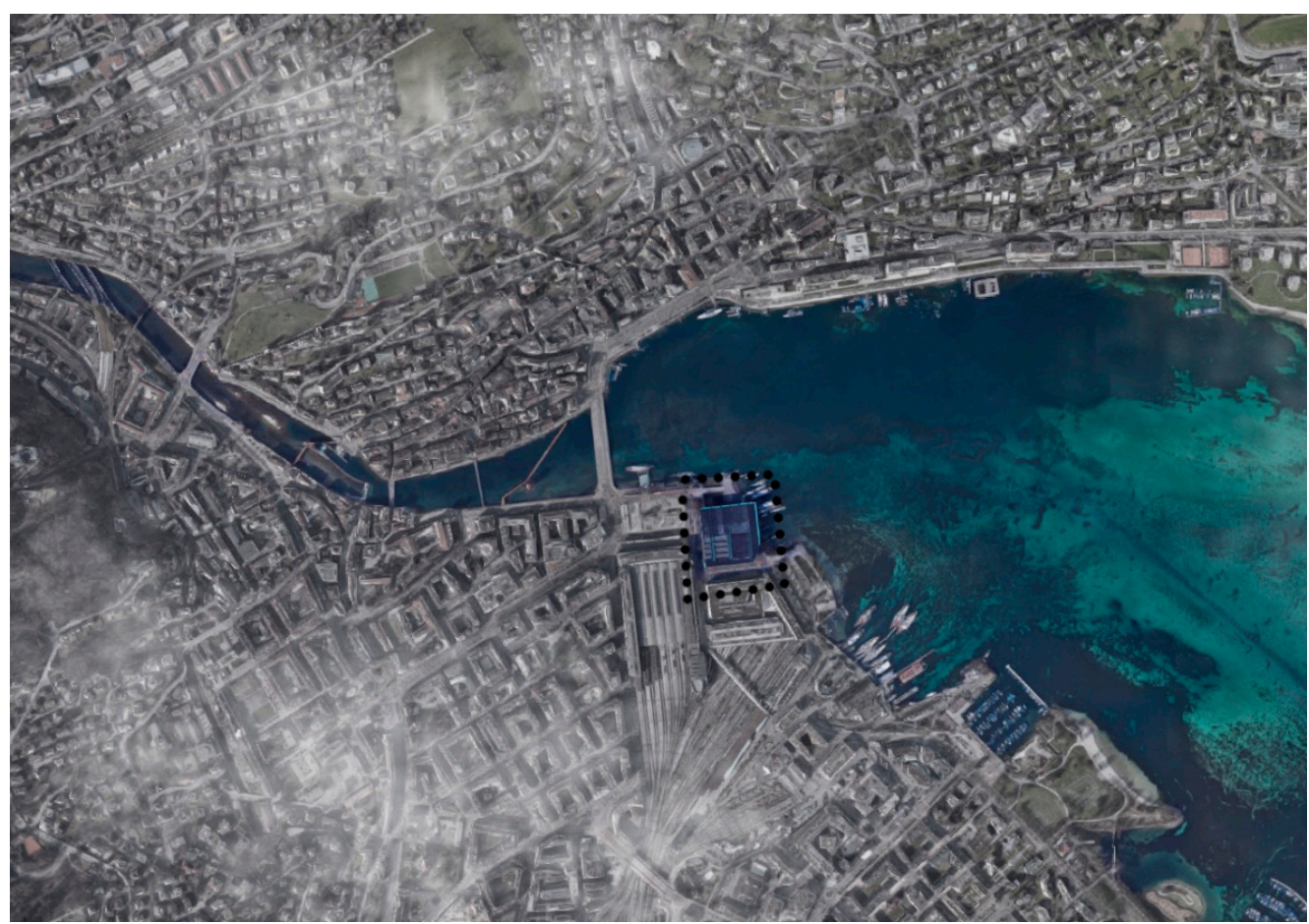

Figure 7. Location of Kultur- und Kongresszentrum Luzern in the city of Lucerne, Switzerland, graphic processing by E. Latusek.

In the late 1980s, after Hayek's research on the optimization of cultural spaces in Luzern, a publisher and the patron of art-Alice Bucher donated 960,000 Swiss francs to the city to design a new concert venue. In 1989, architects Jean Nouvel and Emmanuel Cattani from Paris won the competition. However, the city authorities and the Concert Venue foundation decided that Rodolphe Luscher from Geneva would carry out the project. In 1991, the old building lost its protection under the conservation area policy, which enabled the possibility of erecting a new Kultur- und Kongresszentrum Luzern. After three years of work, Rodolphe Luscher abandoned the project and the concept by Jean Nouvel was revived.

\subsubsection{Architect and the Concept}

For many years, a French architect Jean Nouvel, has designed buildings so that they create a "visual landscape" fitting into the context they are erected in (sometimes by contrasting with the surroundings). Nouvel studied at École des Beaux-Arts in Paris and was both the founder and a member of Mars 1976 and Syndicat de l'Architecture. During his career, Jean Nouvel received many prestigious awards. In 2008, he received Pritzker Architecture Prize for elegant, yet frequently extravagant and experimental projects (Bill Lacy wrote "Since the beginning of his architectural career in the 1970s, Frenchman Jean Nouvel has broken the aesthetic of modernism and post-modernism to create a stylistic language of his own. He places enormous importance on designing a building harmonious with its surroundings" [21]). Projects by Jean Nouvel transform landscapes they are built in, frequently in themselves becoming the primary urban events, as is perfectly illustrated with an example of the KKL (Figure 8). In an interview published in El Croquis in 2002, the architect said "Everything is theatrical. ( . . ) scenography is the relationship between objects and matter that we want to display to somebody who is watching. In effect, in every building there is a way of proving a three-hundred-and-sixty degree view over the landscape, as in Lucerne" [28]. 


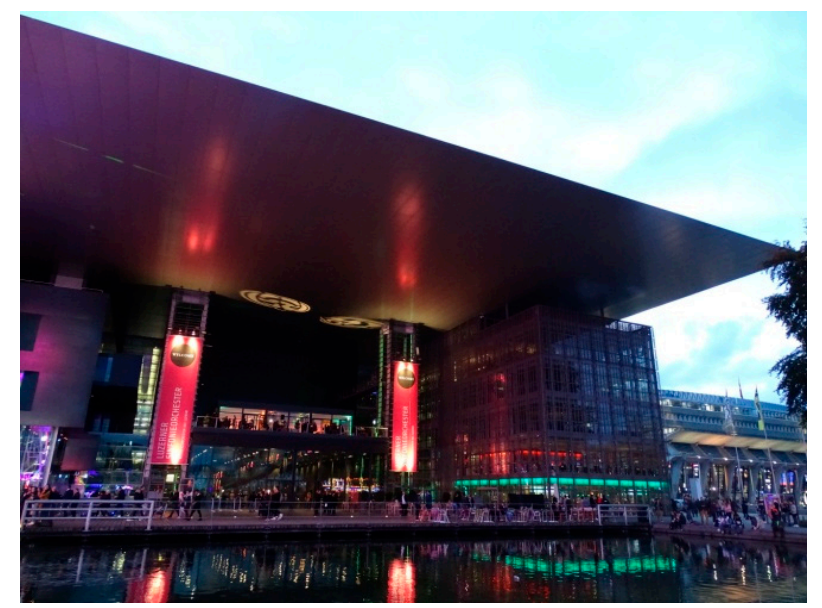

Figure 8. Façade of Kultur- und Kongresszentrum Luzern viewed from Europaplatz (Europe Square), photograph by B. Majerska-Pałubicka.

In the competition phase, Jean Nouvel was stunned with the staggering view of the vast mountainous landscape and Lucerne's bridges. The initial design of Kultur- und Kongresszentrum Luzern assumed the location of the centre on the surface of the lake [29]. The idea soon proved environmentally and legally unfeasible. The architect transformed his concept and, instead of locating the building on the lake surface, let water enter the building, which was standing on the shore. The primary issue was the relationship between the centre and two existing buildings characterized by large cubature, i.e., the old post office (since 2011 - the University of Lucerne) and, interesting, in terms of its form, the Central Railway Station, whose fragment was designed by Santiago Calatrava. Nouvel wanted to take advantage of the vicinity of the lake and of the Old Town. The architect decided that it was necessary to create an autonomous place counter-balancing nearby buildings, yet at the same time emanating calm and assimilating the landscape. Wishing to proportionally adjust the scale of the internal spaces of the building to the scale of the city, Nouvel noted that "One ought to remember that the project is extraordinary in the relatively small city of Luzern-even Paris does not have a concert hall seating two thousand spectators and provided with such facilities and infrastructure" [30].

The new building of the Culture and Congress Centre in Luzern is inscribed in the context in following the "principle of inclusion", the primary elements of which are Lake of the Four Forested Settlements (Lake Lucerne) and the Reuss River (Figure 9). The residents had courage to accept the introduction of an innovative project in the city space. In 1994 Luzern's electorate approved 94 million of Swiss francs for the construction of KKL (65.7\% votes in favor). A year later, the construction of the new Culture and Congress Centre was initiated. The building was erected in a record-breaking time of 5 years [29]. Due to environmental issues, the centre was not built on the lake but water was allowed to enter the building interior and form a water garden provided with footbridges. Vast terraces under the roof of the KKL enable visitors admire the enchanting landscape of the lake and mountains. In the foyer, panoramic windows frame views of the bay and the Old Town. Jan Nouvel says that "Each window in the foyer is like a photograph; all this is connected with the relationship between the interior and the exterior" [30]. The unique nature of the project is also connected with the unusually active participation of Lucerne residents, collaborating, through numerous referenda, with the architect at various stages.

\subsubsection{Building and Functional-Spatial Solutions}

The KKL is an excellent example of modern architecture. Visitors from all over the world come to the centre on business and for entertainment. The centre hosts cultural events and conferences. Jean Nouvel writes that "The building divided into three basic modules under one monolith canopy resembles three ships moored to the shore. Each of 
the ships is different but all of them complement one another well" [30] (Figure 10). The architect adjusted the building structure to the existing context so that the former could not dominate the latter. The functional modules are structurally distinguished and separated with three huge skylights, two of which light up spaces above the water ducts located inside the building (Figure 10).

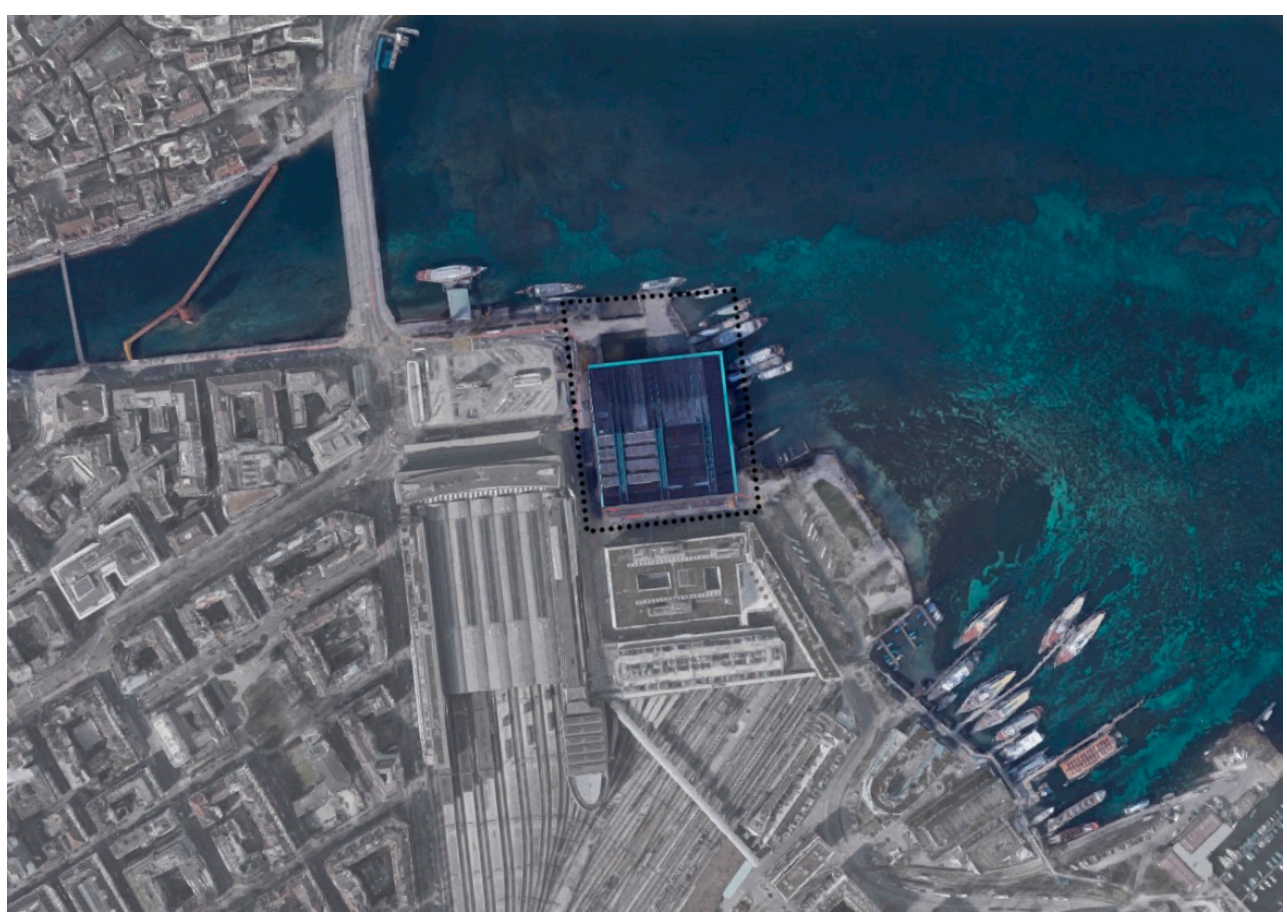

Figure 9. Context of Kultur- und Kongresszentrum Luzern, graphic processing, based on Google Maps by E. Latusek.

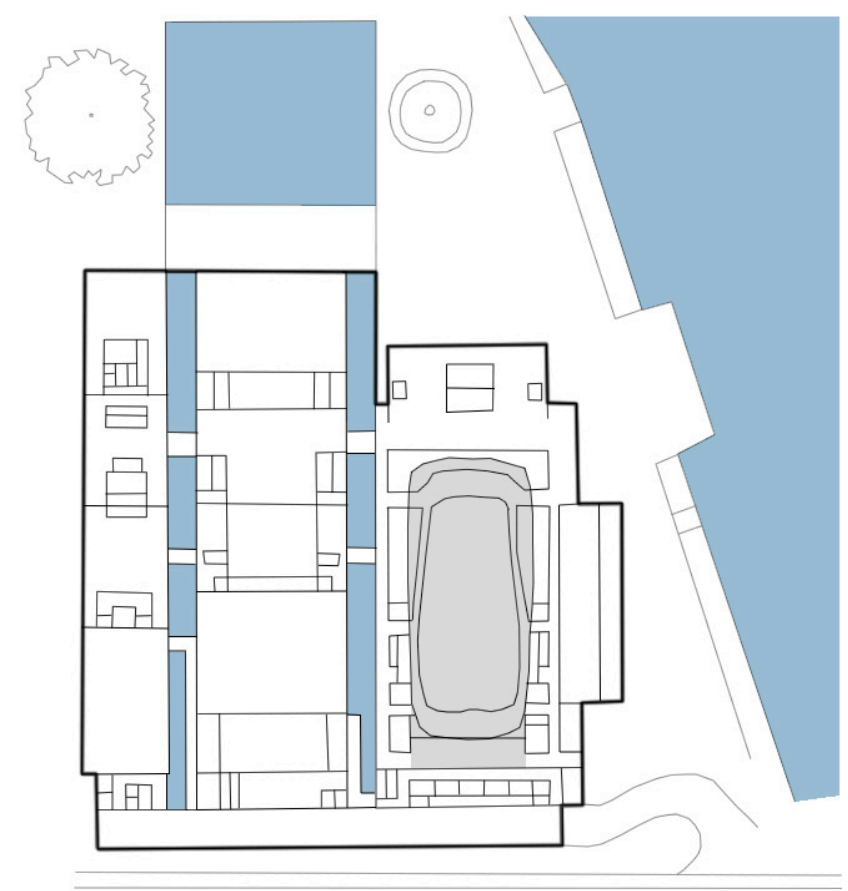

Figure 10. Projection of Kultur- und Kongresszentrum Luzern, graphic processing, based on [29] by E. Latusek. 
The Europe Square (Europaplatz), constituting the front area of the KKL from the north side, is extended in the central body of the building (Figure 11b,c). The central part of the centre houses a multifunctional hall for conferences, banquets and concerts. The versatility of the hall is provided by moving partitions and technical facilities including an audio-video system, adjustable stage and a mobile stand. The first floor houses an auditorium for 270 spectators. The second floor contains six freely adjustable and versatile conference rooms. The third floor houses business and media spaces and offices created for purposes of KKL Luzern and KKL Luzern Management AG. The story also houses the "Museum of Art Lucerne" (having an area of $2000 \mathrm{~m}^{2}$ ) [31], regarded as one of Switzerland's most important museums, staging temporary exhibitions of national and foreign artists. The space designed for exhibition purposes is architecturally neutral and allows the full expression of art.

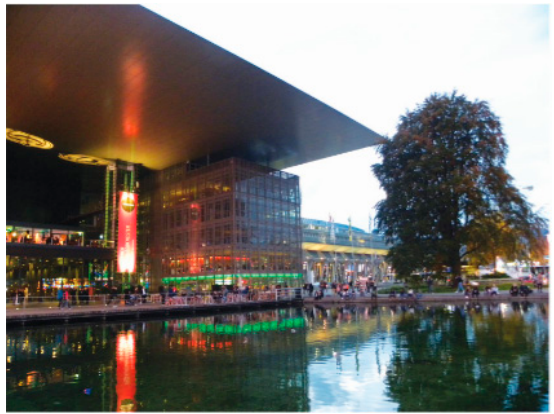

(a)

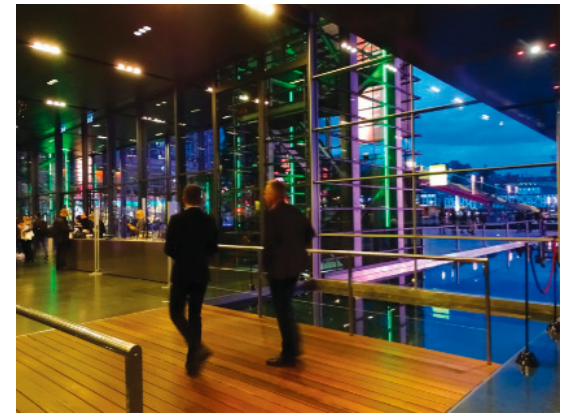

(b)

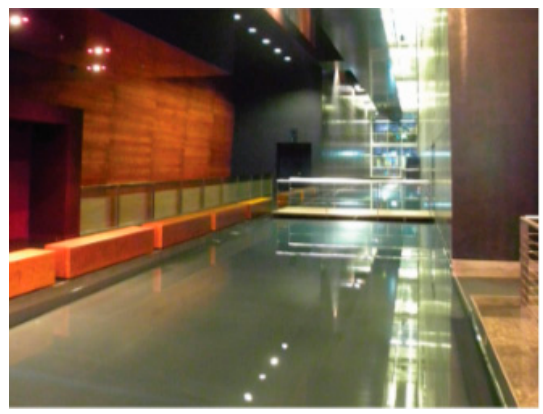

(c)

Figure 11. Kultur- und Kongresszentrum Luzern: (a) front façade seen from Europaplatz and (b, c) water ducts between the modules of the building; photograph by B. Majerska-Pałubicka.

The module on the west side houses World Café and Restaurant RED, organizing various gastronomic events. The zone also includes a showroom, a multifunctional room and an events hall (with a foyer) for 300 spectators. Visitors can use one of the terraces located on the last story just under the vast roof of the centre.

The building service facilities are located on the south side, vis à vis the university. The three modules are "shifted" towards the central body of the building and are connected through technical facilities, utility rooms and circulation routes. The connections between the modules enable the interaction of individual functions (Figure 11). The south façade, austere in its form, hides an internal access road, which is located behind it. The façade from Lucerne Railway station resembles a see-through bird cage with a metal façade condensed in areas requiring coziness (Figure 11). The year 2001 saw the sum-up of the total cost of construction. Final calculations revealed that the erection of the building cost 226.5 million Swiss francs and was by 32.5 million francs higher than planned initially. The window panes present engraved names of sponsors and donors, who contributed over 50 million francs to the KKL construction fund.

\subsubsection{Concert Hall (Salle Blanche)}

The main concert hall, seating as many as 1840 spectators, is located in the third (eastern) module of the KKL body, on the side of Lake of the Four Forested Settlements (Lake Lucerne). Owing to its shape characterized by curvatures, the hall resembles the soundbox of a string instrument. Sometimes referred to as the Salle Blanche (Figure 12), the hall owes its name to its slightly curved white side walls covered with gypsum reliefs. The interior is finished with bright wood (Oregon pine, cherry tree, maple and beech) with seats padded with dark blue color (Figure 13). In the summer, during concert intervals, spectators can use a large terrace offering a breath-taking view of the lake, the mountains and the opposite wharf. The acoustic properties of the concert hall (adjustment to music styles from the Middle Ages to contemporary music) were given the highest priority. The 
world famous acoustics of the "Salle Blanche" attracts renowned orchestras, conductors and soloists. The height from the stage plane to the ceiling amounts to as many as $22 \mathrm{~m}$. The acoustics is the achievement of a New York architect Russell Johnson, commonly known as one of the world-class leading acoustic engineers (along with his Artec group (Figure 12)). The "Salle Blanche" was designed having classical music in mind. The venue was adjusted to music, not vice versa.

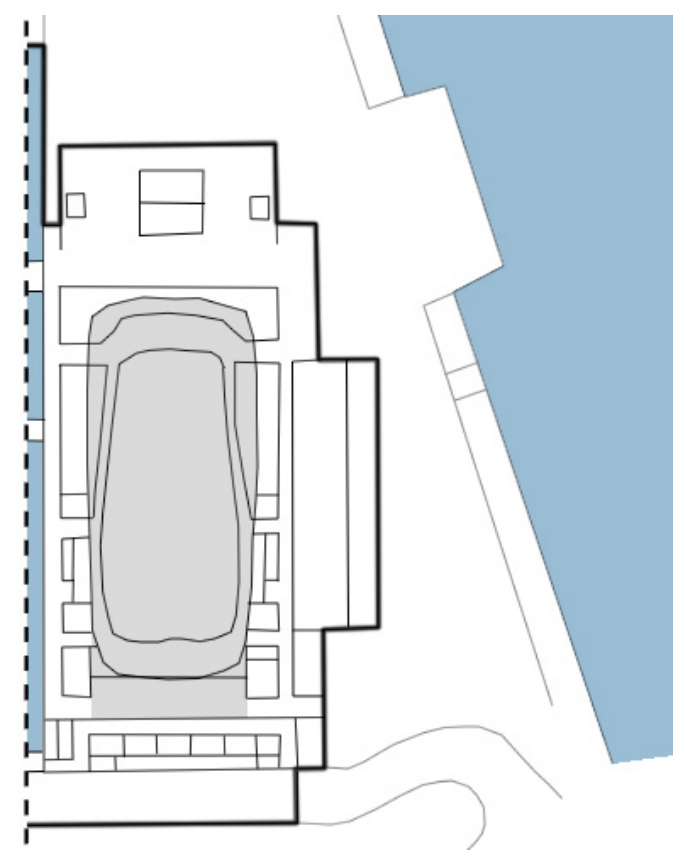

Figure 12. Salle Blanche in Kultur- und Kongresszentrum Luzern, graphic processing by E. Latusek.

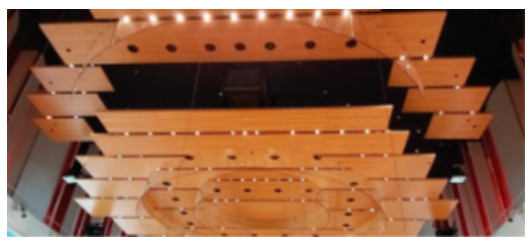

(a)

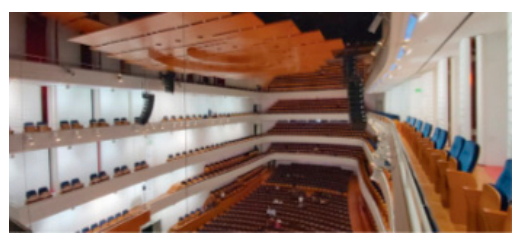

(b)

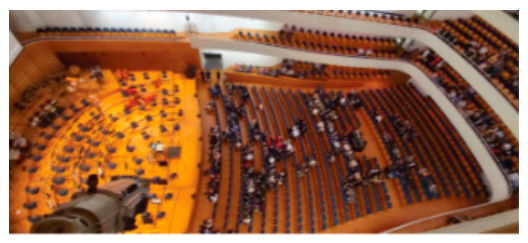

(c)

Figure 13. Salle Blanche in Kultur- und Kongresszentrum Luzern: (a) ceiling acoustic panel; (b) interior and the view of the circles and (c) interior and the view of the stalls; photograph by B. Majerska-Pałubicka.

Concrete acoustic panels are attached using motor-driven hinges. By opening the panels, the volume of the hall increases by $7000 \mathrm{~m}^{3}$. A reverberation chamber has a form of large empty space located behind the stage at the upper circle level. The vast void behind the panels and a computer-aided control system enable the modification of acoustic effects as requested by the conductor and thus satisfying the requirements of the music to be performed (Figure 14). The time of reverberation can also be adjusted using special curtains inside the chamber. The combination of the panels and curtains enables fine tuning of the hall acoustics. The hall also features curtains separating the panels from the hall interior. With uniformly covered planes, the time of reverberation is shorter; this functionality is used during vocal events such as conferences and intentionally amplified music [30]. 


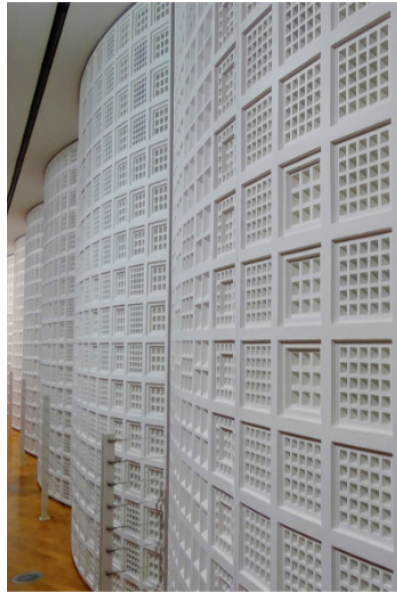

(a)

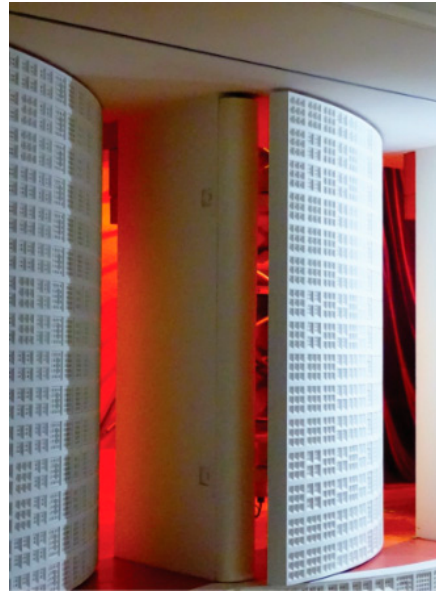

(b)

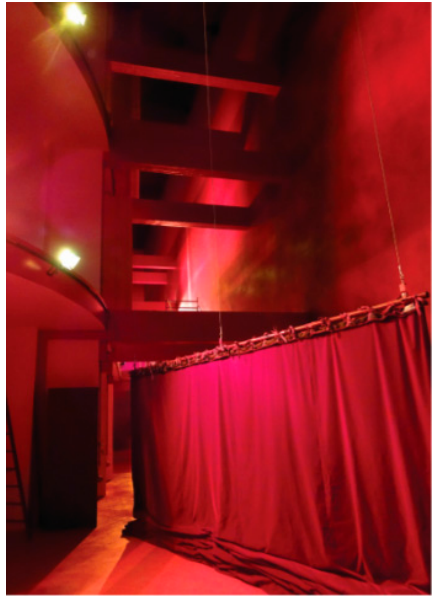

(c)

Figure 14. Salle Blanche in Kultur- und Kongresszentrum Luzern-acoustic system: (a,b) mobile panels and (c) acoustic chamber with the curtain; photograph by B. Majerska-Pałubicka.

\subsection{Changsha Meixihu International Contemporary Art Museum (MICA), Changsha, China}

2.6.1. City and the Problem

Changsha is an administrative centre of the Hunan province with a harbor on the Xiang Jiang River (with several tributaries within the city limits), at the foot of sacred Mount Heng (Hengshannanor Nanyue) (Figure 15). The city is the largest and most versatile cultural centre of the Hunan province. Being an important transport centre located on historical trade routes, the city needed a venue enabling the combination of three important institutions, i.e., the Grand Theatre, a multifunctional theatre and Contemporary Art Museum MICA, so that they do not compete but harmonize with one another.

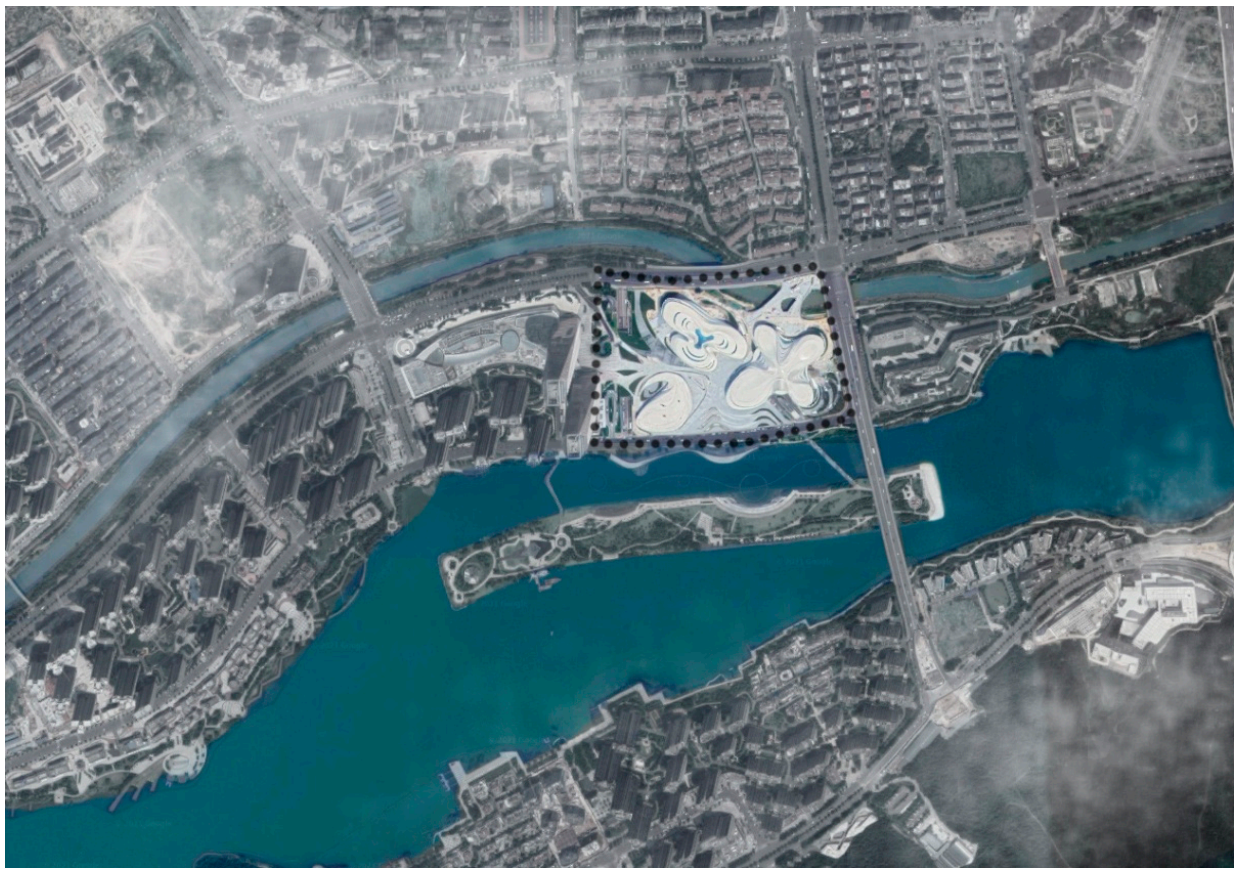

Figure 15. Location of Changsha Meixihu International Contemporary Art Museum in the city of Changsha, China, graphic processing by E. Latusek. 


\subsubsection{Architect and the Concept}

For over four decades, Zaha Hadid Architects (ZHA) seated in London, established in 1979 by late Zaha Hadid (the winner of the most important awards granted by civic, professional and academic institutions all over the world, including the Pritzker Architecture Prize) has been one of the most innovative architectural design studios [32]. Collaborating with customers of worldwide reputation, the ZHA has defined the architecture of the 21st century anew due to imagination-stimulating projects.

Studying the solutions used in the Changsha Meixihu International Contemporary Art Museum (MICA) it is easy to recognize the characteristic style of the ZHA founder (Figure 16). The year 2019 was a very important year for the studio as, apart from the MICA, Zaha Hadid Architects were also responsible for the construction of the international Daxing Airport in Beijing and the Leeza Soho skyscraper in Beijing and a new luxury hotel in the International Youth Cultural Centre in Nanjing [33]. Each of the dynamic and innovative projects was based on more than thirty-year long revolutionary exploration and investigation in combined fields of architecture and urban planning. In her intelligence-based design Hadid always emphasized the importance of the correlation between architecture and the landscape in connection with experimentation with new state-of-the-art technologies. In Hadid's designs, natural topography and technological systems are always well integrated, leading to surprising, ambiguous and dynamic forms.

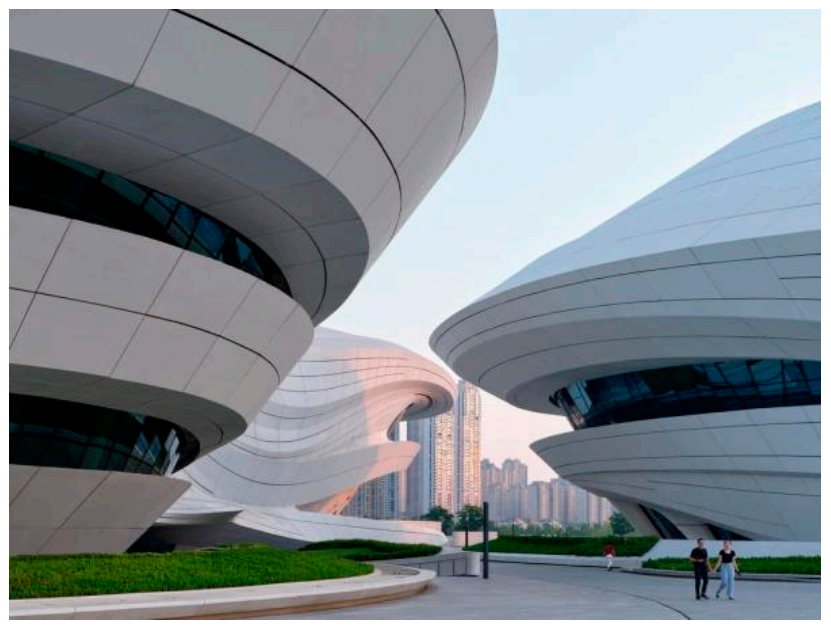

Figure 16. Façade of Changsha Meixihu International Contemporary Art Museum viewed from the main square; the photograph source: the official website of (zaha-hadid.com accessed on 8 December 2020) [34].

Due to the concept of Zaha Hadid Architects (ZHA), Changsha, being home to the Grand Theatre staging popular performances and TV productions, has become one of the country's leading media centers [35].

In an interview with Dezeen in 2013 (when the project started), Patrik Schumacher (who has been running the studio since 2016) referred to the development and plans related to the concept of a multifunctional complex in Changsha saying "Embodying values of functionality, elegance and innovation, the Changsha Meixi Lake International Culture $\&$ Arts Centre aims to become the new cultural and civic node for the city of Changsha, as well as global cultural destination ( ... ) Although these civic institutions are uniquely defined and separate, they supply each other in all respects within its setting with plazas offering visitors a tapestry-like sequence of urban ambiances that relate to the different institutions and inject the site with urban vitality" [36] (Figure 17). 


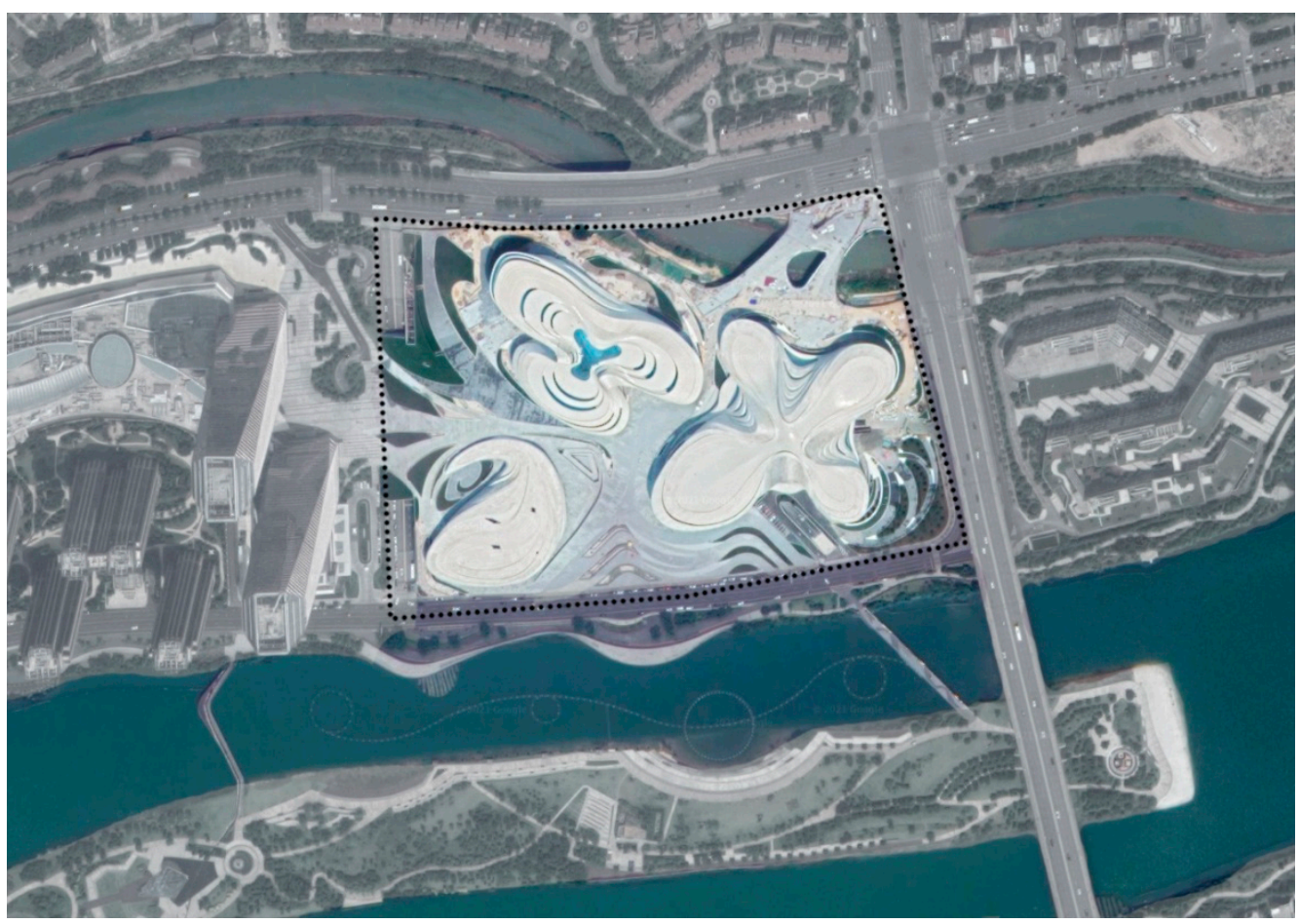

Figure 17. Context of Changsha Meixihu International Contemporary Art Museum, graphic processing, based on [37] by E. Latusek.

The architectural appearance of the Changsha Meixihu International Contemporary Art Museum (MICA) with façades made of GRC (glass-reinforced concrete) panels [37] somehow constitutes the continuation of "Zaha's signature" in a new and unique shape. It forms a refined and elegant outline of the hibiscus flower, which is reflected through a special structure (the curtain wall made of reinforced concrete) [38].

\subsubsection{Building and Functional-Spatial Solutions}

The Changsha Meixihu International Contemporary Art Museum has become an important landmark of the Hunan province. This dynamic composition combines social, economic and environmental aspects of the idea of sustainable development, reinforcing the relationship between the buildings and their widely defined context. The white "fluid" façades made of GRC contrasted with vast glazing give the complex almost "cosmic", out-of-this-world appearance [33,36]. The organic architectural language (characteristic of Zaha Hadid Architects) also translates into the development of land around the complex of the buildings along with "flowing" footpaths (similar to the façades of the buildings) taking into account the necessity of maintaining the appropriate ratio of a biologically active area (environmental aspect). The complex is divided into three formally separate, yet constituting the entirety, buildings located around footways cutting across the area. Between the three bodies there are external yards where outdoor events and sculpture exhibitions are held [35]. The above-presented land development is additionally reinforced by the object location by the Longwanggang River. Within the project, the ZHA has planned also the construction of two footpaths connecting the multifunctional complex with the Festival Island (located on Lake Meixi) and providing access to parks and walking paths [36].

The above-mentioned institutions having a total area of $115,000 \mathrm{~m}^{2}$ have been designed in a manner enabling the maximum continuity of activity - the Grand Theatre opens when the Contemporary Art Museum starts to close, whereas the variety of events in the Small Theatre makes it function for nearly twenty four hours (economic aspect) [35]. As a result, the complex sustains city vitality, providing users with various attractions at any time of 
the day and night (social aspect). The complex also includes gastronomic and commercial functions, which supplement program solutions.

Due to the selected aspects of functional-spatial solutions, among the three main bodies of the MICA complex, the focus was directed towards the Grand Theatre (Figure 18) as it could be used in comparison with the KKL and the ACROS. The front area of the Grand Theatre is a spacious square characterized by gradual (stepped) development, going down towards the Longwanggang River. The body of the Grand Theatre, Changsha's largest arena seating up to 1800 spectators, is the central element of the complex. The interior has all necessary functions including an irregularly configured biomorphic lobby, cloakrooms, bars, restaurants, guest apartments and VIP rooms and indispensable accessory functions, i.e., administration offices, rehearsal rooms, dressing rooms, wardrobes, etc. [35]. The main concert hall was designed having in mind the widest range of performing arts. The internal space of the hall is lined with wood and finished with "flowing" cream-colored ceiling, whirling upwards like a "sandstorm" [33].

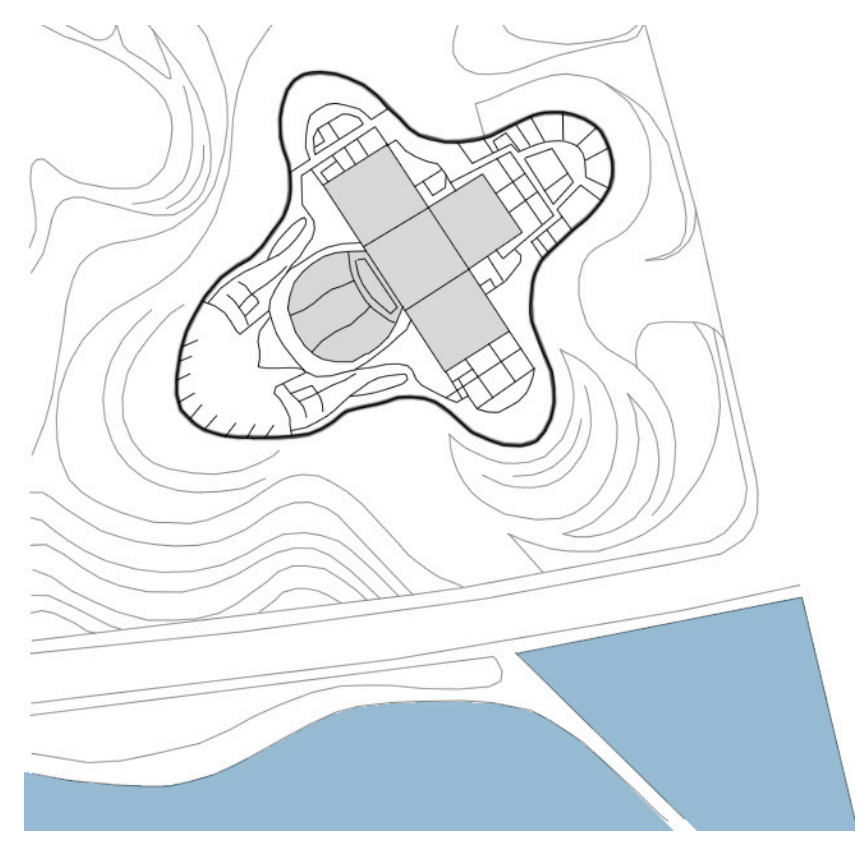

Figure 18. Projection of Changsha Meixihu International Contemporary Art Museum, graphic processing, based on Google Maps and [32], by E. Latusek.

The smallest of the three MICA buildings is the small theatre performing the role of a multifunctional room seating up to 500 spectators. It is characterized by a highly flexible layout as its hall can be freely transformed and configured to address various needs, including small theatrical performances, fashion shows, music concerts, banquets and commercial events [35].

The third building is the Contemporary Art Museum, the last of the structures erected within the eight-year-long project. Its primary architectural feature is a large atrium with extensive boomerang-like glazing. The space bathed in light was designed to serve the purpose of various types of events. Three "wings", "growing" from the main atrium, contain a workshop area, a lecture theatre, a café and a museum shop [35]. The building is connected with external space, i.e., the front area constituting outdoor exhibition space. Zaha Hadid Architects designed the museum in such a way so as "to use the unique location of the place along with its surrounding views" [36]. From one side, it is possible to enter a square, which forms open-air exhibition space. 


\subsubsection{Concert Hall (Hunan Grand Theatre)}

In the concept of the concert hall, Zaha Hadid Architects aimed to obtain "fluid" space with an asymmetric auditorium. The hall has many streamlined surfaces and internal concave light slits affecting its acoustic quality and resulting in, among other things, the concentration of sound or the lack of lateral reflection (Figure 19). The primary challenge was the complexity of the acoustics of the asymmetric concert hall where acoustic control is very difficult. To obtain the ideal combination of sound quality and the architectural modeling of the hall, ZHS, in conjunction with various companies (e.g., Beilida) used various software programs for acoustic calculations and measurements of models in appropriate scales, experimentations and other technical measures enabling the optimization of the general shape, structure and materials of the building as the entirety [39]. The Beilida company developed "a relevant construction technology of the hyperbolic GRC curtain wall to implement a high-precision, fully screwed, adjustable, removable and specially shaped GRC curtain wall" [38]. According to Zaha Hadid Architects: "Our research into opera house and auditorium design over the past 20 years has shown us the many benefits of asymmetrical auditoriums - they can give a real depth to the natural acoustics. All the three acoustic parameters-reverberation, sound pressure (volume) and clarity-need to be balanced, and we worked very closely with Marshall Day to optimize the performance of the space. One example; ribs in the glass-fibre reinforced gypsum (GFRG) panels enable the sound pressure to be toned down. The deeper and closer together these ribs are, the more effective they are at toning down the pressure." [32]. The undulating interiors were finished with glass fiber-reinforced gypsum (GFRG) [32]. The interior of the main concert hall of the MICA's Grand Theatre is champagne gold-colored space with glossy finishing resembling luxurious silk. Seats are copper-colored. The overhead lighting is composed of small white LEDs resembling the nocturnal horizon.

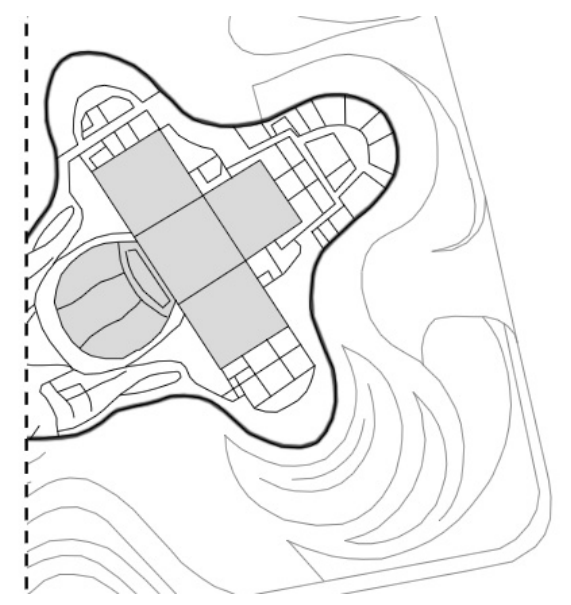

Figure 19. Hunan Grand Theatre in the Changsha Meixihu International Contemporary Art Museum.

\section{Results}

\subsection{Multiple Case Study-Multifunctional Buildings}

The theory of intelligence-based design holds that the close relationship between the mind and the matter, i.e., the direct neurological assessment of existing surfaces, patterns, textures and forms, can be referred to the code of architecture. Through the determination of such a code, the architect can define the framework of a given project. Each of the architects being the authors of the concepts of the buildings subjected to investigation approached the design process differently and recognized specific solutions as the most important (Table 1). In architecture, there is no casus of one proper solution. Design is always a process, the results of which may always surprise in different ways and on various planes. Looking at each of the three selected designs, it is possible to notice that their bodies relate to axioms constituting primary geometric solids in architecture. The 
use of intelligence-based design by the creator enables the development of basic shapes and their consolidation and the transformation of the matter. Each of the above-named buildings is differently inscribed in the context of its surroundings, yet none of them ignores the needs of pedestrian users. Within the development of land belonging to the buildings, under each structure there is a large underground car park enabling the separation of pedestrian circulation and vehicle traffic.

Table 1. Comparison of the bodies of investigated objects: Prefectural International Hall "Asian Cross Road Over the Sea"ARCOS Fukuoka, Kultur- und Kongresszentrum Luzern-KKL Luzern and Changsha Meixihu International Contemporary Art Museum with the purpose of summarizing the conducted multicriterial case study in the context of intelligence-based design-descriptive and graphic comparison.

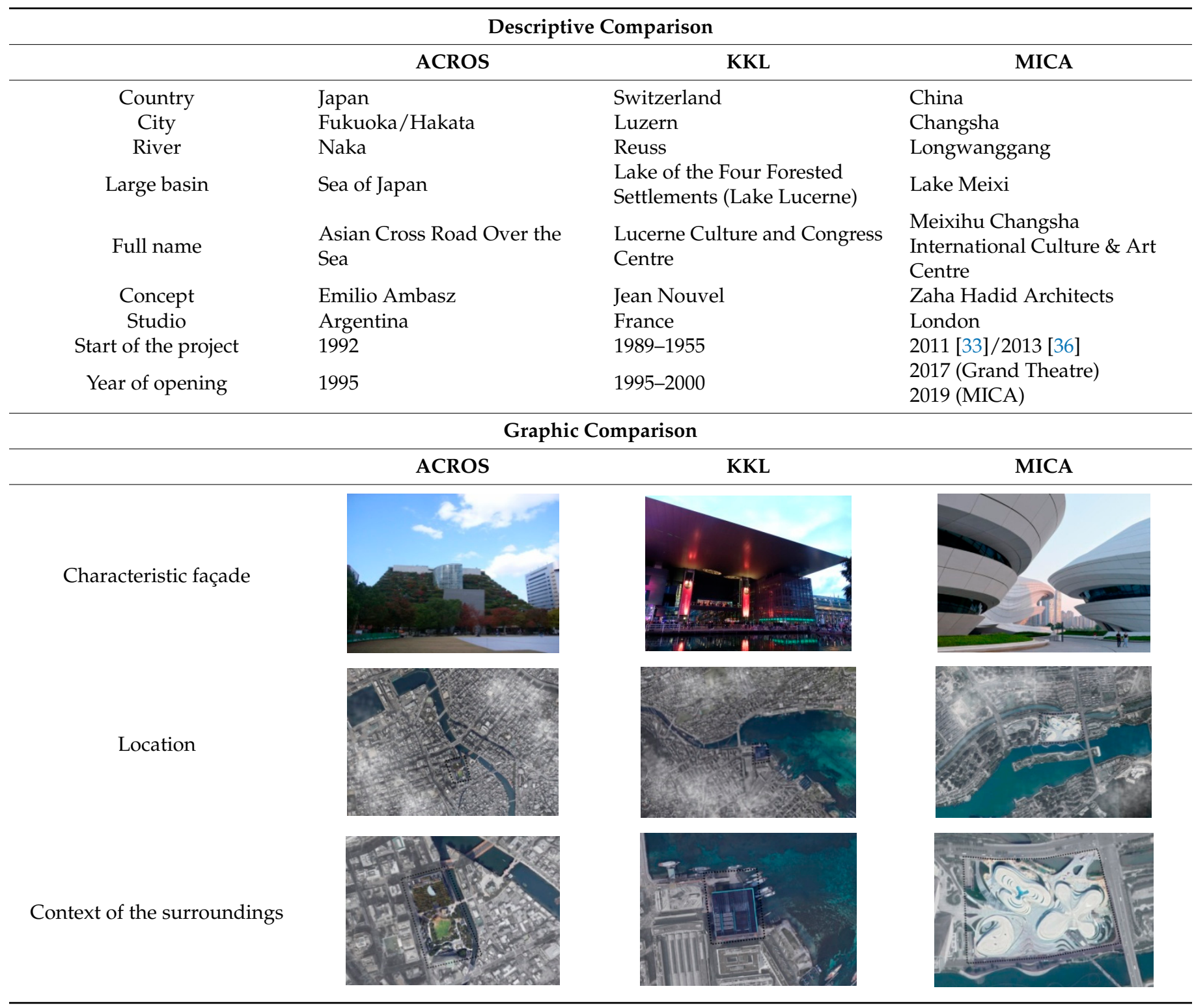


Table 1. Cont.

Comparable projections Descriptive Comparison

The chronological comparison of the structural systems revealed the technological progress, which has taken place over the past 30 years: from the already complicated structure decreasing the heat island effect of the ACROS, through the spectacular structure (including the long span roof) of the multifunctional KKL, to the complex of three buildings constituting the entirety of the MICA and characterized by a complicated, non-linear and organic shape.

In terms of the analysis of functional-spatial solutions, each of the buildings features primary functions: ACROS-government offices, commercial spaces and recreation for the city residents, KKL—opera, museum of art and congress centre, whereas MICA—Grand Theatre, Small Theatre and Meixihu International Contemporary Art Museum (MICA). In addition, the buildings feature repeated functional elements including museums of art (ACROS: Takumi gallery, KKL: Museum of Art in Luzern and MICA: Contemporary Art Museum), concert halls (of comparable size, seating approximately 1800 spectators), external terraces, multifunctional rooms, information centers, exhibition areas, conference rooms, auditoria, offices, shops, gastronomy, areas for outdoor events and underground car parks. The comparable systems of projections (and of the concert halls) can also be related to the aforementioned axioms of geometric solids.

All of the above-named buildings are located on the waterfront in city centers and have main external squares integrating them with the surrounding urban space.

Each of the investigated design concept differently approaches the theory of intelligencebased design. Emilio Ambasz preparing the spatial solution of the ACROS proves that in densely populated cities it is possible to interweave developers' interests (economic aspects), the need for new buildings (social aspect) and open public space (environmental aspect). Jean Nouvel, in spite of the fact that the KKL "encroaches" on Luzern's regional nature, creates a new value in compliance with the concept of sustainable development fully addressing stakeholders' needs (economic aspect), satisfying residents' needs (social aspect) and fully respecting the natural environment (environmental aspect). The intelligence-based design developed by Zaha Hadid Architects is based on the already well-proven strict relationship between architecture and the landscape (environmental aspect), thus continuing "Zaha's signature" in a new and unique shape and the revival of urban space (economic and social aspects). 


\subsection{Multiple Case Study-Concert Halls}

The research discussed in the article includes the descriptive analysis of the following concert halls (Table 2): Fukuoka Symphony Hall (ACROS), Salle Blanche (KKL) and Hunan Grand Theatre (MICA). The above-named concert halls have many things in common. Each of the halls can seat approximately 1800 spectators, features acoustic equipment enabling the adjustment to various types of music and houses a smaller hall, seminar rooms and rooms for music rehearsals. Each of the halls serves local music festivals (ACROS: Fukuoka Early Music Festival, ACROS Classic Festa, Karuta Festival; KKL: Blue Balls Festival, Lucerne Festival and MICA: Events on Festival Island). In each of the buildings, spectators can use vast terraces offering magnificent views of the city and waterside areas.

Table 2. Comparison of concert halls in the studied buildings: Fukuoka Symphony Hall, Salle Blanche and Hunan Grand Theatre, summarizing the multicriterial case study—descriptive comparison.

\begin{tabular}{|c|c|c|c|}
\hline \multicolumn{4}{|c|}{ Descriptive Comparison } \\
\hline & ACROS & KKL & MICA \\
\hline Name & Fukuoka Symphony Hall & Salle Blanche & Hunan Grand Theatre [40] \\
\hline Design & $\begin{array}{l}\text { Emilio Ambasz in collaboration } \\
\text { with Nihon Sekkei, Takenaka } \\
\text { Corporation [20] }\end{array}$ & Russell Johnson, Artec group & $\begin{array}{l}\text { Marshall Day, Beilida } \\
\text { Company }\end{array}$ \\
\hline Number of spectators & 1867 & 1840 & 1800 \\
\hline Type of music & $\begin{array}{l}\text { orchestral performances, chamber } \\
\text { music, music competitions, } \\
\text { recitals, scientific conferences, } \\
\text { lectures }\end{array}$ & $\begin{array}{l}\text { classical music, adaptation to } \\
\text { music styles from mediaeval } \\
\text { to contemporary music }\end{array}$ & $\begin{array}{l}\text { widest range of performing } \\
\text { arts }\end{array}$ \\
\hline Acoustics & $\begin{array}{l}\text { mobile stage with reverberation } \\
\text { screens-acoustic reflectors }\end{array}$ & $\begin{array}{l}\text { concrete acoustic panels on } \\
\text { motor-driven hinges, large } \\
\text { reverberation chamber with } \\
\text { curtains }\end{array}$ & $\begin{array}{l}\text { asymmetrically curved } \\
\text { interior surface, hyperbolic } \\
\text { curtain wall GRC, GFRG }\end{array}$ \\
\hline Interior & $\begin{array}{l}\text { interior finished with wood, } \\
\text { white ceiling coffers with } \\
\text { suspended chandeliers }\end{array}$ & $\begin{array}{l}\text { white gypsum relief panels, } \\
\text { bright wood (Oregon pine, } \\
\text { cherry tree, maple, beech) }\end{array}$ & $\begin{array}{l}\text { interior lined with wood and } \\
\text { "fluid" cream-colored ceiling } \\
\text { making the impression of a } \\
\text { "sandstorm" }\end{array}$ \\
\hline Seats & black & dark blue & shade of copper \\
\hline Festivals & $\begin{array}{l}\text { ACROS Classic Festa, Fukuoka } \\
\text { Early Music Festival, Karuta } \\
\text { Festival }\end{array}$ & $\begin{array}{l}\text { Blue Balls Festival, Lucern } \\
\text { Festival }\end{array}$ & Events on Festival Island \\
\hline
\end{tabular}

\section{Discussion}

\subsection{Continuation of the Design Concept}

Investigating each of the above-presented multifunctional buildings (Table 3), it is possible to notice that their bodies relate to axioms constituting primary geometric solids in architecture. The use of intelligence-based design by the designer enables the development of basic shapes and their consolidation and the transformation of matter. In terms of the ACROS, the pyramid constituting the initial point was appropriately cut and completed with two elements providing the body with unique nature. The author of the KKL building concept flattened a cuboid (taking into account Luzern's low housing) and added to it a wide flat roof reaching far beyond the building outline. The ZHA approached the issue in a very "plastic" way, providing the body with a "fluid" shape and ovality. In each case, the section is the confirmation and continuation of design decisions concerning the shaping of the body. In each of the above-presented examples it was possible to observe the characteristic location of multi-space car parks under the surface of the ground-the solution, which has been applied for many years. Car parks along with technical accessory 
facilities constitute the foundation of the body. In the investigated buildings, the specific façade provides a broader image of the subjective treatment of detail. It is possible to notice the addition of further bodies to the basic shape, which is the case with the ACROS and $\mathrm{KKL}$, or providing the body with more detail by the necessity of adding windows or entrances in a manner unspecified by basic norms.

Table 3. Graphic comparison of the buildings' bodies subjected to research: Prefectural International Hall "Asian Cross Road Over the Sea", Kultur- und Kongresszentrum Luzern and Changsha Meixihu International Contemporary Art Museum, presenting the primary assumptions connected with intelligence-based design.

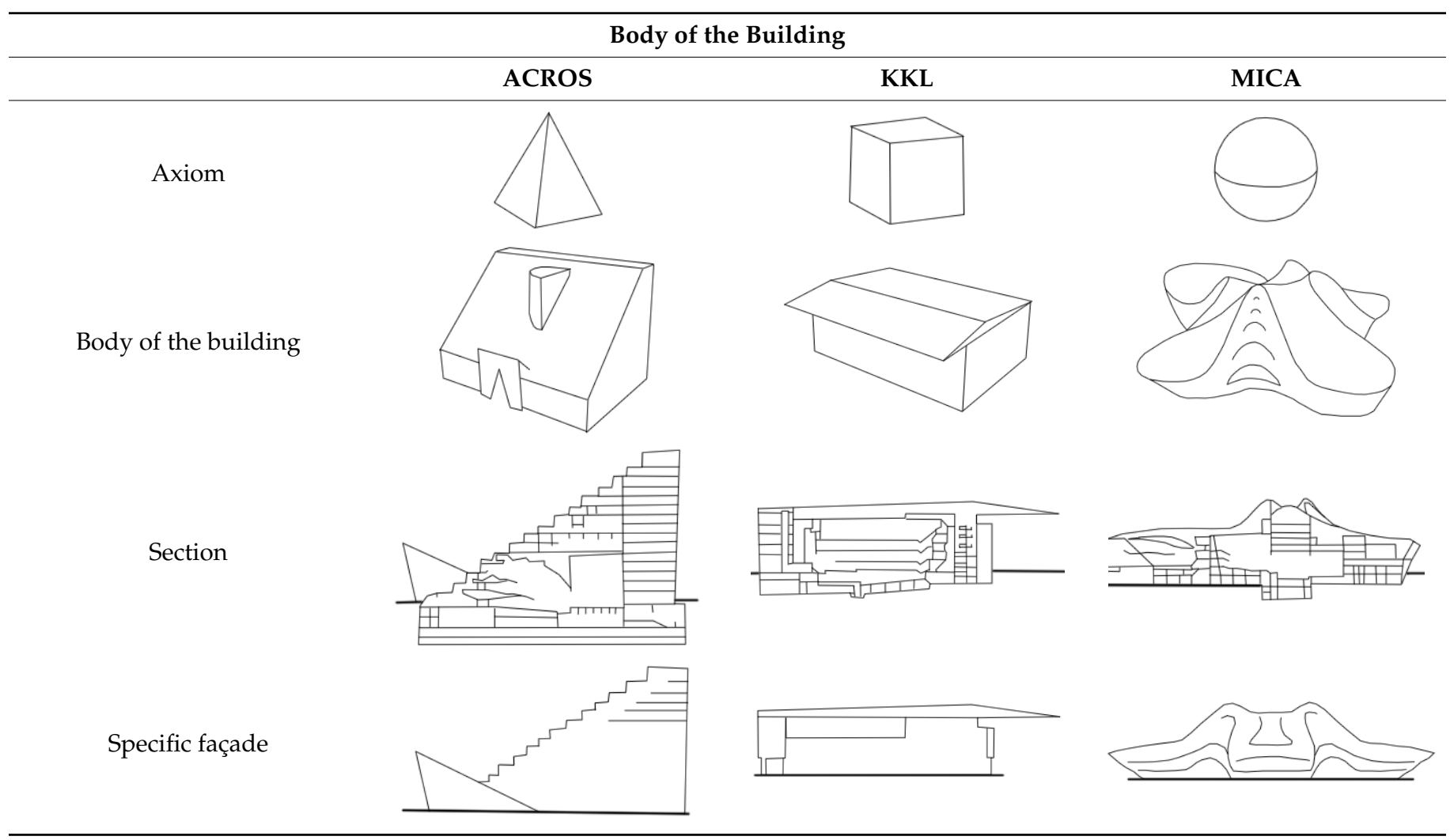

Graphic processing by E. Latusek.

\subsection{Intelligence-Based Design}

An important research question formulated in the article was: "Why, at the design stage, is it so important to expertly use intelligence-based design?". Assuming that the architect should not at any cost include individual design-related trends (hi-tech, environmental, etc.) but is rather obliged to combine their various aspects for the common good of the building users, it was demonstrated that the aforesaid assumption significantly applies to smart buildings designed for smart cities, which should harmonize not only systemically but also in relation to such currently important issues as sustainable development and design for people.

Long before environment-related discussions became popular worldwide, Emilio Ambasz's works were characterized by the reinterpretation of the relationship between architecture and landscape. The architect is regarded as one the founding fathers of the pioneer trend of green architecture. Ambasz believed that architecture must be pragmatic, yet its main reason for existence is to stir emotions. As the method of design used by the architect is timeless, his "design behaviour" can still inspire subsequent generations of architects. Ambasz's use of intelligence-based design resulted in the complete elimination of any delays in the ACROS construction due to possible social challenges and lack of acceptance. While designing the ACROS, the architect reconciled opposite needs, i.e., the maintaining of the original size of the Tenjin Central Park (very important for Fukuoka's 
residents) and providing the city with an extensive multifunctional centrally located structure. The architect designed the building so that the park space would continue on terrace roofs, thus integrating (as much as possible) the building with public space.

The KKL building, designed by Jean Nouvel, is inscribed in the context following the "principle of inclusion", the primary elements of which are Lake of the Four Forested Settlements and the Reuss River. At the stage of competition, Jean Nouvel was overwhelmed by the staggering view of the vast mountainous landscape and Luzern's bridges. Due to environmental issues, the centre was not built on the lake but the water was allowed to enter the building interior and form a "water garden" cut across by footbridges. Another important issue identified by the architect was the relationship between the centre and two existing buildings characterized by large cubature, i.e., the old post office and the Central Railway Station, the fragment of which was designed by Santiago Calatrava. Nouvel, in accordance with the theory of intelligence-based design, took advantage of the vicinity of the lake and of the old town and adjusted the building structure to the existing context so that the former could not dominate the latter. The architect divided the building into three "... basic modules under one monolith canopy resembling three ships moored to the shore. Each of the ships is different but all of them complement one another well" [30]. The connections between the modules enable the interaction of the individual functions of the building.

Through projects that stimulated imagination worldwide, Zaha Hadid Architects has defined anew the architecture of the 21st century. Each of the dynamic and innovative projects was based on more than thirty-year long revolutionary exploration and investigation in combined fields of architecture and urban planning. In her intelligence-based design Hadid always emphasized the importance of the strict correlation between architecture and landscape in connection with experimentation with state-of-the-art technologies. This usually resulted in unorthodox and dynamic solutions of forms, e.g., exemplified by the complex of MICA buildings, which constitute the entirety in spite of being separate bodies.

The ability to read the physical environment constitutes an evolving set of abilities to process information. The human mind has developed this capability over thousands of years due to direct experience. Research on architecture continually provides information about possibilities of improving the environment by human intelligence. The buildings subjected to the research demonstrated that smart buildings are something much more than technological novelties and electronic design. It is definitely worth using the theory of intelligence-based design, which emphasizes the existence of a close relationship between the mind and the matter and constitutes the direct neurological evaluation of an existing surface, structure, pattern, texture and form. In all of its forms, architecture must be based on structural principles present in the physical world. In addition, a smart building can be complex both structurally and technologically but it does not need to be more complicated than necessary. In this case, technology is an important tool, not a goal in itself. In the intelligence-based design, a certain idea is a point of departure, which constitutes the basis for further design. The architect builds a paradigm, on which their further design-related decisions are based. In spite of structural advancement, large cubature and the complexity of the functional-spatial system, the buildings have conceptually coherent bodies that properly address stakeholders' needs and satisfy the requirements of sustainable development.

\subsection{Collaboration with Stakeholders and Functionality}

Another question posed in the article is to what extent the architect should respond to stakeholders' (developers, city dwellers, etc.) wishes and how it relates to the rational transformation of the matter directed at functionality and satisfaction of social aspects?

Emilio Ambasz's concept (Figure 20a) fully addressed the need for green areas in expensive Japanese central urban districts and, at the same time, provided the possibility of generating profit without escalating the conflict with the city residents. The project uses a number of garden terraces, which by the fact of "rising" give back to the residents of 
Fukuoka nearly the entire park greenery taken from them by the building. The concept also proves that in densely populated cities it is possible to interweave developers' interests, the need for new buildings and open public space. The ACROS has become a meeting place both for Fukuoka's residents and tourists travelling throughout Japan. For instance, the Takumi Gallery housing a permanent exhibition of traditional crafts, which are important to the city, has become a tourist destination visited by many.

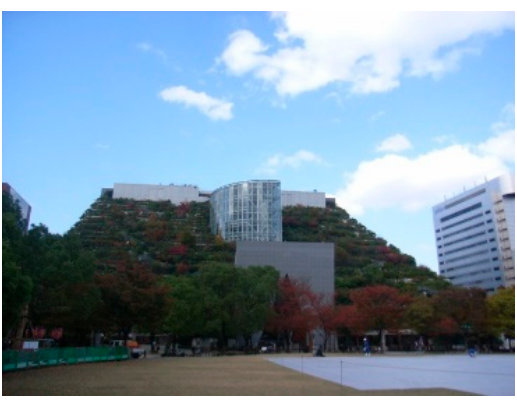

(a)

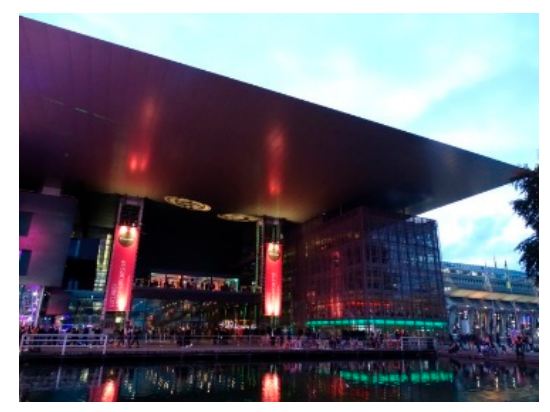

(b)

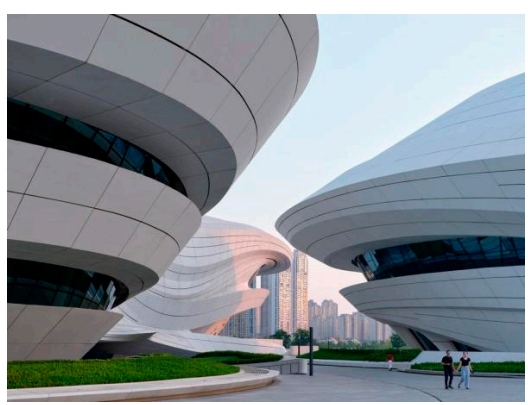

(c)

Figure 20. Views of investigated buildings: (a) Prefectural International Hall "Asian Cross Road Over the Sea", photograph by B. Majerska-Pałubicka; (b) Kultur- und Kongresszentrum Luzern, photograph by B. Majerska-Pałubicka and (c) Changsha Meixihu International Contemporary Art Museum, the photograph sourced from the official website of zaha-hadid.com [34].

By designing the KKL, Jean Nouvel created an autonomous place counter balancing nearby buildings, yet at the same time emanating calm and assimilating the landscape (Figure 20b). The unique nature of the design was also connected with the unusual participation of the Lucerne residents, collaborating, through numerous referenda, with the architect at various stages. The residents had the courage to accept the introduction of an innovative project in the historic city space. The lobby window panes show engraved names of sponsors and donors, who contributed over 50 million francs to the KKL construction fund. Since its erection, the KKL has been an excellent example of modern architecture open to visitors from all over the world. Guests who visit the centre come there on business, seek entertainment or wish to extend their cultural awareness.

The concept of the Changsha Meixihu International Contemporary Art Museum (Figure 20c) resulted in the creation of a new centre of culture and social spaces for the city of Changsha. Due to the building, Changsha continues to be one of the country's leading media centers. Within the project, the ZHA planned the construction of two footpaths connecting the multifunctional complex with the Festival Island (located on Lake Meixi) and providing access to parks and walking paths [36]. The Grand Theatre is the venue of popular performances and TV productions. In addition, the three institutions of the complex have been uniquely defined through different but complementing opening hours. As a result, the complex contributes to the vitality of the city, providing Changsha residents with various attractions at any time of the day and night.

\section{Conclusions}

During the investigations conducted in the scope of three selected multifunctional objects, the researchers focused on the issues connected with the cities where the buildings are located and their social and spatial problems. The figures of the buildings' creators were outlined and the impact of their concepts on the location, form, surroundings and functional-spatial solutions of the designed objects was presented. The studies also encompassed concert halls, which constitute an inherent part of the objects bonding their different functions together. All this enabled the researchers to make an attempt to answer the research questions posed at the beginning of this paper.

- Is it possible to find the continuation of the design concept in the context of smart design in the buildings subjected to research? 
- Why is it so important to expertly use intelligence-based design at the design stage?

- To what extent should the architect respond to stakeholders' (developers, city dwellers, etc.) wishes and how does it relate to the rational transformation of matter, taking into account functionality and adjustment to social and ecological aspects?

Despite the fact that the studied multifunctional objects differ from one another in terms of their form, there is no doubt that they show the continuation of the design idea in the context of intelligence-based design. The application of intelligence-based design makes it possible to develop basic shapes into complex structures. The bodies of the studied multifunctional objects allude to axioms constituting basic geometrical bodies in architecture. However, they were developed by the authors of architectural concepts on such a scale that it brought a whole new dimension to the solutions addressing users' needs and issues. Intelligent thinking about designing does not focus solely on the solutions connected with form and function, but it broadens the architect's horizons enabling thus the search for solutions, which break designing deadlocks. The architectural object is not treated as a mere matter, but as a response to neurological external stimuli resulting in the reaction in the form of a design. There is no single good solution in architecture. In this case, each designer had to refer to a different location or individual social or spatial issues. That is why the designers selected particular solutions as the best and aptest. The architect may make use of intelligence-based design, similarly to Emilio Ambasz, to solve problems of all interested parties. Designs such as the KKL or MICA — being embedded in the context of surroundings and yet preserving their pure modern form-constitute the reflection of the rational transformation of matter.

Author Contributions: Conceptualization, B.M.-P.; Data curation, E.L. and B.M.-P.; Formal analysis, B.M.-P.; Funding acquisition, E.L. and B.M.-P.; Investigation, E.L.; Methodology, E.L.; Project administration, E.L.; Resources, E.L.; Software, E.L.; Supervision, B.M.-P.; Validation, B.M.-P.; Visualization, E.L.; Writing—original draft, E.L.; Writing—review and editing, B.M.-P. All authors have read and agreed to the published version of the manuscript.

Funding: This research received no external funding.

Institutional Review Board Statement: Not applicable.

Informed Consent Statement: Not applicable.

Data Availability Statement: The data presented in this study are available on request from the corresponding author.

Conflicts of Interest: The authors declare no conflict of interest.

\section{References}

1. Salingaros, N.A.; Mehaffy, M.W. Geometrical fundamentalism. In A Theory of Architecture; Umbau-Verlag: Solingen, Germany, 2006; pp. 172-194.

2. Parametric Design. Available online: www.blog.strefakursow.pl (accessed on 3 September 2020).

3. Bagiński, J. Architektura otwartego kodu. In Produkcja-Metoda; Warsaw University of Technology: Warsaw, Poland, 2013; pp. 13-18.

4. Smart Architecture Is. Available online: www.o2.org/ideas/smartarch/smartarch987 (accessed on 3 September 2020).

5. Buckman, A.H.; Mayfield, M.; Beck, S.B.M. What is a Smart Building? In Smart and Sustainable Built Environment, 1st ed.; Emerald Group Publishing: Bingley, UK, 2014; Volume 3, pp. 92-109.

6. Understanding the Elements of Smart Architecture. Available online: www.designblendz.com (accessed on 20 July 2020).

7. Nature and Architecture: Emilio Ambasz and Fukuoka's ACROS Centre-25 Year Later. Available online: https://www.ambasz. com/fukuoka-25th-anniversary (accessed on 15 November 2020).

8. Salingaros, N.A.; Masden, K.G. The Science of Intelligent Architecture; Published in English/Polish; Teka Komisji Urbanistyki i Architektury: Krakow, Poland, 2017; pp. 95-105.

9. Alexander, C.; Ishikawa, S.; Silverstein, M. A Pattern Language; Oxford University Press: Oxford, UK, 1977.

10. Connected Vehicles in Smart Cities: The Future of Transportation Published. Available online: https://interestingengineering.com (accessed on 25 November 2020).

11. McLaren, D.; Agyeman, J. Sharing Cities: A Case for Truly Smart and Sustainable Cities; MIT Press: Cambridge, MA, USA, 2015.

12. The 3 Generations of Smart Cities. Available online: https:/ / www.fastcompany.com (accessed on 25 November 2020). 
13. Yin, R.K. Case Study Research: Design and Methods, 4th ed.; SAGE: Thousand Oaks, CA, USA, 2009; pp. 1-183.

14. Foqué, R. Building Knowledge in Architecture; University Press: Brussels, Belgium, 2010.

15. Majerska-Palubicka, B. Zintegrowane Projektowanie Architektoniczne w Kontekście Zrównoważonego Rozwoju. Doskonalenie Procesu; Wydawnictwo Politechniki Śląskiej: Gliwice, Poland, 2014.

16. Prefectural International Hall: Project Information. Available online: https://www.ambasz.com/fukuoka-prefecturalinternational (accessed on 15 November 2020).

17. Fukuoka Prefectural International Hall. Available online: www.archello.com (accessed on 11 November 2020).

18. Amazing Green Building: The ACROS Fukuoka. Available online: www.metaefficient.com (accessed on 25 November 2020).

19. ACROS Fukuoka Prefectural International Hall by Emilio Ambasz Turns 25. Available online: www.stirworld.com (accessed on 11 November 2020).

20. Featured Project: ACROS Fukuoka Prefectural International Hall. Available online: www.greenroofs.com (accessed on 11 November 2020).

21. ACROS Fukuoka Foundation: Cultural Promotion Projects. Available online: https://www.acros.or.jp/english/about/ (accessed on 15 November 2020).

22. Facility Guide: Fukuoka Symphony Hall. Available online: https:/ /www.acros.or.jp/english/floor/symphony.html (accessed on 25 November 2020).

23. Facility Guide: Floor Map. Available online: https:/ / www.acros.or.jp/english/floor/floormap.html (accessed on 25 November 2020).

24. Niedoceniana Perełka Szwajcarii. Available online: www.podroze.se.pl (accessed on 28 January 2020).

25. Blue Balls Festival. Available online: www.blueballs.ch (accessed on 3 February 2020).

26. Lucerne Festival. Available online: www.lucernefestival.ch (accessed on 3 February 2020).

27. KKL Official Website: History. Available online: https://www.kkl-luzern.ch/en/dienstleistungen/das-kkl-luzern/geschichte (accessed on 28 January 2020).

28. The Pritzker Architecture Prize: Jean Nouvel Biography. Available online: www.pritzkerprize.com (accessed on 21 December 2020).

29. KKL Luzern: Architect Jean Nouvel + Acoustic Engineer Russell Johnson. Available online: www.en.wikiarquitectura.com (accessed on 12 December 2020).

30. KKL Luzern Management AG. In KKL Luzern Media Documentation, 1st ed.; KKL Luzern Management AG: Luzern, Switzerland, 2016; pp. 1-18.

31. Museum of Art Lucerne: Art at the KKL Luzern. Available online: https://www.kkl-luzern.ch/en/your-visit/general-info/ kunstmuseum-luzern (accessed on 14 February 2020).

32. Changsha Meixihu International Culture and Arts Centre: Zaha Hadid Architects. Available online: www.theplan.it (accessed on 2 December 2020).

33. Signature Curves Define Zaha Hadid-designed Arts Center. Available online: www.newatlas.com (accessed on 23 March 2020).

34. Zaha Hadid Architects: Changsha Meixihu International Culture \& Arts Centre. Available online: www.zaha-hadid.com (accessed on 8 December 2020).

35. Inaugural Exhibition: Changsha Meixihu International Culture and Art Centre by Zaha Hadid Architects. Available online: www.metalocus.es (accessed on 8 December 2020).

36. Zaha Hadid Architects' Lakeside Cultural Centre Nears Completion in Changsha. Available online: www.dezeen.com (accessed on 7 December 2020).

37. Changsha Meixihu International Culture \& Arts Centre by Zaha Hadid Architects. Available online: www.detail-online.com (accessed on 2 December 2020).

38. Zaha's Signature. Available online: www.aalborgwhite.com (accessed on 23 March 2020).

39. Whipped Peaks form Zaha Hadid Architects' Meixihu Cultural Centre. Available online: www.wallpaper.com (accessed on 8 December 2020).

40. Venue: Hunan Grand Theatre-Changsha. Available online: www.bachtrack.com (accessed on 8 December 2020). 